ZOOLOGIA 32 (6): 497-531, December 2015

http://dx.doi.org/10.1590/S1984-46702015000600010

\title{
Taxonomic review of Berthella and Berthellina (Gastropoda: Pleurobranchoidea) from Brazil, with description of two new species
}

\author{
Juliana Alvim ${ }^{1, *} \&$ Alexandre Dias Pimenta ${ }^{1}$
}

\author{
'Departamento de Invertebrados, Museu Nacional, Universidade Federal do Rio de Janeiro. Quinta da Boa Vista, \\ São Cristóvão, 20940-040 Rio de Janeiro, RJ, Brazil. \\ *Corresponding author. E-mail: juju_alvim@yahoo.com.br
}

\begin{abstract}
Berthella currently comprises five valid species recorded from the western Atlantic, of which only Berthella agassizii (MacFarland, 1909) and Berthella stellata (Risso, 1826) have been recorded from Brazil. Two species of Berthellina occur in Brazil: Berthellina quadridens (Mörch, 1963) and Berthellina circularis (Mörch, 1863); however, based on a literature review and the anatomical study presented here, we only recognize $B$. circularis as occurring in the country. This study gives a detailed re-description of B. agassizii, B. stellata and B. circularis based on material from Brazil, and adds two new species to the genus, from the Brazilian coast, Berthella punctata sp. nov. and Berthellina ignis sp. nov. Berthellina circularis and $B$. quadridens are considered distinct species based on the denticulation of the radular teeth. $B$. quadridens presents the majority of teeth with two denticles, rarely three-four denticles, while in $B$. circularis from Brazil the radular teeth are highly denticulate with up to 17 denticles. Berthella and Berthellina do not form a monophyletic group, and cluster in a large polytomy within Pleurobranchidae. A detailed anatomical study is performed to improve the understanding of the evolutionary history of Pleurobranchidae. The comparison with available data on the odontophoric muscles of Pleurobranchoidea shows that Berthella and Berthellina present a pair of the muscle m10v that connects the mj with the ventral portion of the m5, while in Pleurobranchus and Pleurobranchaea the m10v connects the mj with the ventral portion of the m4; Berthella and Berthellina do not present the muscle m10d, which is present in Pleurobranchus and Pleurobranchaea. Based on these characters, Berthella seems to be more closely related to Berthellina than to Pleurobranchus.
\end{abstract}

KEY WORDS. Berthella punctata sp. nov.; Berthellina ignis sp. nov.; Pleurobranchidae; western Atlantic.

Members of Pleurobranchidae are generally characterized by body oval to elongated with centralized rhinophores, internalized plate-like shell, gill exposed on the right side of the body and veil trapezoidal. The family is currently composed of seven genera: Bathyberthella Willan, 1983; Berthella Blainville, 1824; Berthellina Gardiner, 1936; Boreoberthella Martynov \& Schrödl, 2009; Pleuredhera Ev. Marcus \& Er. Marcus, 1970; Pleurobranchus Cuvier, 1805; and, Tomthompsonia Wägele \& Hain, 1991. Berthella and Berthellina have an intricate taxonomic history due to their similarities in external morphology and consequent misidentifications through the years (e.g., GARDINER 1936). The elongated teeth with numerous subterminal denticles in Berthellina clearly distinguish these two genera. Berthella resembles Berthellina in the external morphology, but in characters of the radula, jaws and reproductive system, it is more similar to Pleurobranchus (WILLAN 1983).

Berthella is one of the most species-rich genus of Pleurobranchidae, with 29 valid species, while Berthellina presents only 13 valid species. Berthella and Berthellina generally occur in tropical and warm temperate waters and range from the intertidal zone to moderate subtidal depths (WILLAN 1987). These genera are well known because some of their species are widespread geographically and rather common (e.g., Berthella stellata (Risso, 1826) and Berthellina citrina Ruppell \& Leuckart, 1828). However, Berthella and Berthellina are not well-established clades, following recent phylogenetic studies that have failed to support them, and according to which species of these two genera cluster in a large polytomy inside Pleurobranchidae (MARTINOv \& SCHRÖDL 2009). Berthella currently comprises five valid species recorded from the western Atlantic, of which only Berthella agassizii (MacFarland, 1909) and Berthella stellata are recorded from Brazil (GARCíA et al. 2008, Rios 2009). Berthella tupala Er. Marcus, 1957 was described from São Paulo, Brazil, but it is currently considered a junior synonym of $B$. stellata. Besides that, PADula et al. (2012) recorded an undescribed morphotype of Berthella from Alagoas, Brazil.

Two species of Berthellina are recorded from the western Atlantic: Berthellina circularis (Mörch, 1863) and Berthellina quadridens (Mörch, 1963), both originally described from St. Thomas and recorded from Brazil, respectively from Pernam-

2015 | Sociedade Brasileira de Zoologia | www.sbzoologia.org.br | www.scielo.br/zool All content of the journal, except where identified, is licensed under a Creative Commons attribution-type BY. 
buco (Ev. Marcus 1984), and from Alagoas and Bahia (Ev. Marcus \& Er. Marcus 1969, Padula et al. 2012, Ev. Marcus 1979). Berthellina circularis and B. quadridens have a confused taxonomic history, since some authors considered them as synonyms (e.g., THомpson 1977, VALDÉs et al. 2006) while others recognized them as two distinct species (e.g., Ev. Marcus 1984).

In this study, we re-describe the species of Berthella and Berthellina from Brazil, with the aim of improving the taxonomical delimitation of these species. Most of them were described based on one or two preserved specimens, and subsequent records only expanded their geographical distribution, without adding information on their morphology. Moreover, two new species from Brazil are described, one from each genus.

\section{MATERIAL AND METHODS}

Descriptions of the external morphology were based on living and preserved specimens. Dissections and drawings of the digestive system, including intrinsic and extrinsic muscles of the odontophore, the reproductive system, the nervous system and the circulatory system were performed under a stereomicroscope with a drawing tube.

The radula and jaw were cleaned in $10 \%$ potassium hydroxide $(\mathrm{KOH})$, subsequently rinsed in water and mounted for examination in a Jeol JSM-6390LV scanning electron microscope (SEM).

The nomenclature used to name the portions of the gill follows Willan (1983) and the one used for the odontophore muscles follows PONDER et al. (2008: 350-351, figs. 13.9-13.10), with additional information added by suffixes (d: dorsal; v: ventral). In the nervous system, when the nerve bifurcates, the number of the nerve is followed by letters, e.g., "a", "b".

In the lists of examined material, the number inside brackets indicates the number of specimens in each lot, followed by the number of specimens dissected.

Anatomical abbreviations: a, anus; ag, duct of acid gland; am, ampulla; bc, buccal ganglion; bg, blood gland; bu, bursa copulatrix; ca, oral canal; ccpb, connective between buccal and cerebropleural ganglia; $\mathrm{cp}$, nerves that leave from the cerebropleural ganglion; cpg, cerebropleural ganglion; cpp, commissure between the pedal ganglia; dd, deferent duct; dg, digestive gland; e, eye; f, female opening; fg, female gland; fo, foot; gi, gill; gm, gill membrane; go, gonopore; hg, hermaphrodite gland; in, intestine; j, jaw plates; $\mathrm{m} 1 \mathrm{~d}$, m1va and $\mathrm{m} 1 \mathrm{vb}$, jugal protractor muscles of odontophore; $\mathrm{m} 4$, main dorsal tensor muscle of radula; m5, accessory dorsal tensor muscle of radula; $\mathrm{m} 10 \mathrm{a}$, ventral tensor muscle of radula; $\mathrm{m} 10 \mathrm{v}$, protractor muscle of odontophore; ma, male opening; mg, metapodial gland; mj, jaw muscle; mo, mouth; mr, retractor muscle; nb, nerves that leave from the buccal ganglion; ne, nephropore; $\mathrm{np}$, nerves that leave from the pedal ganglion; nvg, nerve leading to visceral ganglion; oa, opening of the duct of the acid gland; oe, esophagus; ot, oral tentacle; $\mathrm{p}$, penial papilla; pb, prebranchial aperture; pe, pericardium; pg, pedal ganglion; pgl, penial gland; pr, prostate; ra, radula; rg, rhinophoral ganglion; rh, rhinophore; rn, rhinophoral nerve; rs, radula sac; sd, salivary duct; se, shell; sg, salivary gland; so, opening of the duct of the salivary gland; sr, seminal receptacle; st, stomach; sta, statocyst; va, vagina; vg, visceral ganglion.

The material is deposited in the following Brazilian Malacological collections: Museu de Zoologia, Universidade de São Paulo (MZSP); Museu Nacional, Universidade Federal do Rio de Janeiro (MNRJ). Specimens of other species of Berthella and Berthellina were examined for comparison: Berthella tamiu Ev. Marcus, 1984: MZSP 121400, 21 ${ }^{\circ} 05^{\prime} \mathrm{N}, 86^{\circ} 23^{\prime} \mathrm{W}, 4$ may 1967, John Elliot Pilsbury Cruise 6701 coll. [ 4 microscope slides: radula and jaw; penis; mantle; cerebro-pleural ganglia]; Berthellina quadridens: MZSP 75310, Barbados, Diva coll. [1 dissected specimen + two microscope slides: radula and jaw; penis]; MZSP 121401, Colombia [one microscope slide: radula]; MZSP 121402, Colombia [one microscope slide: radula and jaw]; MZSP 121403, Colombia [one microscope slide: transversal cut of reproductive system]. These microscope slides were recently located among the slides belonging to the collection of Er. Marcus and Ev. Marcus, lodged in the MZUSP. Probably, these slides of $B$. quadridens represent the original material studied by Ev. Marcus $(1976,1984)$ and Ev. Marcus \& Huges (1974) due to the correspondence of localities studied in these papers. Despite the fact that Ev. Marcus (1976) described only one specimen in the description of B. quadridens from Colombia, in these microscope slides we found two radula from specimens from Colombia, both labeled as "Bandel Colombia". Ev. MArcus (1976) received many species donated by Dr. Klaus Bandel, from Colombia, for this work. It is almost certain that one of these slides corresponds to the slide used in the description made by Ev. Marcus (1976).

\section{TAXONOMY}

\section{Pleurobranchoidea Gray, 1827 Pleurobranchidae Gray, 1827 Berthella Blainville, 1824}

Berthella Blainville, 1824: 262. Type-species by original designation: Berthella porosa Blainville, 1824 (= Bulla plumula Montagu, 1803).

Cleantus Leach, 1852: 28. Type species by original designation: Cleantus montagui Leach, 1852 (= Bulla plumula Montagu, 1803).

Bouviera Vayssière, 1896: 116. Type-species by subsequent designation (Odhner, 1926: 22): Pleurobranchus auranticus Risso, 1818.

Gymnotoplax Pilsbry, 1896: 210. Type-species by subsequent designation (Willan, 1978: 339): Pleurobranchus americanus Verrill, 1885.

Berthellinops Burn, 1962: 135. Type species by original designation: Berthellinops serenitas Burn, 1962.

Description (adapted from Willan 1983, 1987, THOMPson 1970, Ev. Marcus 1984). Shelled pleurobranchs; body elliptical 
or convex; mantle relatively smooth; metapodial gland present; shell ovate; gill rachis generally smooth; anal aperture in front of middle of gill membrane; radula teeth hook-shaped, sometimes with a denticle at base of some lateral teeth; without rachidian teeth; mandibular elements with smooth or denticulate blades. Pair of jugal muscles m1d on dorsal view of buccal mass, inserting into m5, connecting to dorsal-anterior end of snout. Pair m4, main dorsal tensor muscle of radula, reduced, originating in lateral region of cartilages, surrounding them ventrally, inserting into subradular membrane. Pair m5, secondary dorsal tensor muscle of radula, large and broad, covering median portions of cartilage, extending up to dorsal region; originating in posterior surface of cartilages; inserting laterally in mj. Pair $\mathrm{m} 7$ absent. Pair m10d (dorsal) absent. A pair of $\mathrm{m} 10 \mathrm{v}$ connected the $\mathrm{mj}$ with ventral portion of $\mathrm{m} 5$. Pair of strong retractor muscles originating in most posterior portion of $\mathrm{m} 5$, separated in anterior portion and jointed in its posterior portion, laying above anterior portion of digestive gland. Penial gland present.

Remarks. The name Cleantus has been considered a junior synonym of Berthella for a long time (WILLAN 1983). The authorship of the name, however, is questioned here. This name was propagated by Gray (1847) as Cleanthus, with the letter " $\mathrm{h}$ ", and the name Cleanthus Gray, 1847 was only listed in that paper, without any description or characterization. Therefore, the name/authorship of Cleanthus Gray, 1847 is not available, since it does not meet the requirements of Article 12.1 of the International Code of Zoological Nomenclature (ICZN 1999). According to the latter, a name needs to be accompanied by a description or a definition of the taxon that it denotes, or by an indication of it. Therefore, the author of Cleantus is LEACH (1852), who provided a description of the genus.

\section{Berthella agassizii (MacFarland, 1909)}

Figs. 1-3, 11-28

Pleurobranchus agassizii MacFarland, 1909: 59-64, pl. 11-12, figs. 43-57; Ihering, 1915: 141.

Bouvieria agassizii: Odhner 1926: 22; Engel, 1927: 110, fig. 26a-c. Berthella agassizii: Er. Marcus, 1955: 117, figs. 66-77; 1958: 57; Ev. Marcus \& Er. Marcus, 1957: 20, figs. 38-39; 1963: 24; 1964: 198; Er. Marcus \& Ev. Marcus, 1970: 53; Ev. Marcus, 1976: 133; 1984: 51, figs. 6-16; Bandel, 1976: 103, fig. 16; Clark, 1984: 93, figs. 37-42; Gosliner \& Bertsch, 1988: 63, figs. 1E; 15-18; Rios, 1994: 206; 2009: 417; Redfern, 2001: 168, pl. 72: fig. 692; Valdés et al., 2006: 110; García et al. 2008: 90; Padula et al., 2012: 8.

Type material. Holotype CASIZ 021162, 1899?, type locality, coll. Mr.Greeley [1]; Paratype: CASIZ 021163 [1] and CASIZ 021164 [1], same date, locality and collector of holotype.

Type locality. Riacho Doce, Alagoas, Brazil.

Description. External morphology (Figs. 1-2, 11-13). Living specimens translucent pale pink to reddish-pink with scattered opaque white spots (Fig. 1); rhinophores rosy; oral veil and gill white (Fig. 2); foot with some rosy pigment randomly disposed (Fig. 2). Living specimens up to $23 \mathrm{~mm}$ in length; length of mature preserved specimens $6-11 \mathrm{~mm}$; width 3-8 mm; length of foot 4-9 mm; width of foot 2-4 mm. Body oval and oblong. Mantle covered foot entirely. Mantle surface ranges from smooth, in juveniles, to slightly reticulate. Oral veil broad and trapezoidal connected with head region (Figs. 2, 13); laterally, oral tentacles with deep notch, corresponding to almost its length. Rhinophores rolled joined at their bases, up to $1 / 2$ of its length. Gill exposed laterally (Fig. 2); $1 / 2$ to $1 / 3$ length of body; main rachis smooth, without tubercles; alternate pinnae; bipinnated pinnae; 11-14 pinnae; 5-6 pinnae free from body wall, attached by branchial membrane (Fig. 12). Anal opening lying approximately above $3^{\circ}-4^{\circ}$ pinnae (Fig. 12). Prebranchial pore opening beside main rachis, slightly above genital pore (Fig. 12). Nephropore under second pinnae. Genital aperture surrounded by collar (Fig. 12). Penis conical and retractable (Fig. 15). Foot slightly pointed at posterior end with elongated metapodial gland in mature specimens (Fig. 13); metapodial gland 0.1 times foot length; anteriorly bilabiated, upper lip notched, smaller than lower one. Eyes localized just behind rhinophores.

Mantle. Spicules not found, probably dissolved by fixation.

Shell (Figs. 19-20). Translucent white to opaque white; subquadrangular in outline; slightly convex profile; approximately two times longer than wide. Length $5.4 \mathrm{~mm}$, width 2.7 $\mathrm{mm}$ (in preserved specimen with $6 \mathrm{~mm}$ in length); and, length: $5.3 \mathrm{~mm}$, width $2.6 \mathrm{~mm}$ (in preserved specimen with $8 \mathrm{~mm}$ in length). Spire with 1.5 whorls. Protoconch smooth (Fig. 20). Lines of growth distinct; immediately after protoconch, with longitudinal sculptures transverse to lines of growth; sculptured portion corresponding $1 / 3$ to $1 / 4$ total length of last whorl (Fig. 20); anterior portion of last whorl smooth. Shell above heart, located anteriorly on left side of body. Shell covering approximately half of length of mantle.

Circulatory system (Fig. 14). Pericardium well developed in anterior portion of body (near cerebro-pleural ganglia). Blood flowing into auricle from gills, kidney and venous sinuses. Efferent branchial vessel connecting gill with the auricle. Auricle on right side, ventricle on left; auricle with thin wall; ventricle muscular. Blood gland small, creamy/pale orange covering left part of pericardium. Blood gland joined to aorta.

Reproductive system (Figs. 15-17). Ampulla thin and elongated, about same width than deferent duct (Fig. 17); curved, but not convoluted. Spermoviduct branching into two ducts, oviduct leading to female gland mass and other duct leading to prostate (Figs. 16-17). Prostatic portion of deferent duct convoluted (Fig. 17). Near deferent duct distal end it joins with elongated penial gland and narrows near into conical penis. Penial gland about two times thicker than deferent duct and approximately of same size of seminal receptacle (Figs. 1617). Penis (in preserved specimen with $8 \mathrm{~mm}$ length: length $0.36 \mathrm{~mm}$; width $0.12 \mathrm{~mm}$ ) (Fig. 15); completely contractible. 
Bursa copulatrix and seminal receptacle join vaginal duct in its middle. Rounded bursa copulatrix; representing $3 / 4$ of length of seminal receptacle. Seminal receptacle stalked and elongated; black (Fig. 17). Vagina not convoluted (Fig. 17); about 1/2 diameter of deferent duct. Vaginal opening immediately ventral to penis. Genital aperture surrounded by fold (Fig. 12).

Nervous system (Fig. 18). Cerebral and pleural ganglia fused and so closely together,connective imperceptible. Eyes located laterally of cerebro-pleural complex; eyes borne upon very short optical nerves (no). Rhinophoral ganglia placed at bases of rhinophores, near cerebro-pleural ganglia; two main nerves leaving from rhinophoral nerves, runing until distal portion of rhinophores; rhinophoral nerves with many secondary nerves, perpendicular in relation to main nerves. Nerves leaving cerebro-pleural ganglia: cp1 inserting latero-ventrally; cp2 inserting dorsally into mantle; cp3 runing laterally, inserting into body wall, in right side nerve entering into mantle near base of gonopore (apparently on male portion) and, in left side, nerve entering into mantle near anterior portion of digestive gland; cp4 runs until most posterior portion of body, inserting into body wall; cp7 innervating latero-ventral side of body wall. Connective between visceral and cerebro-pleural ganglia evident, leaving posterior portion of right cerebro-pleural ganglia. Connective between buccal and cerebro-pleural ganglia leading from most anterior portion of cerebro-pleural ganglia in ventral view. Nerves leaving buccal ganglia: nb1 inserting into esophagus; nb2 inserting into salivary ducts; connective cerebro-pleuralbuccal shortly after nb2. Pedal commissure short, leaving from most anterior posterior of pedal ganglion. Pedal ganglia smaller than cerebro-pleural complex, in antero-posterior order: $\mathrm{np} 1$ inserting ventrally into oral veil; $\mathrm{np} 2$ inserting anteriorly into foot; np3 innervating foot; np4 inserting ventrally into foot and runs until most posterior portion of body.

Digestive system (Figs. 21-28). Pharyngeal bulb not protruded. Mouth longitudinal, in middle of snout tip. Oral canal muscular just posterior to mouth (Figs. 25-26), representing approximately $1 / 3$ of pharyngeal bulb length. Muscle surrounding jaws (mj) strong, pair of large jaws located in its inner surface, mj originating in lateral and dorsal surfaces of oral canal, inserting into lateral and dorsal regions of buccal mass (Fig. 25). Jaws amber, lighter posteriorly; jaw of two plates surrounding radula inside buccal cavity (Fig. 27); elongated, reaching level of radula. Each jaw plate showing alternate rows formed by elongated and denticulate elements with slight cruciform lateral expansion (73 longitudinal and 26 transversal elements, in preserved specimen of $6 \mathrm{~mm}$ long; 69 longitudinal and 32 transversal elements, in preserved specimen of $11 \mathrm{~mm}$ long); elements consist on a main cusp with 3-6 denticles in each side, which could be of different sizes and not symmetric (Fig. 21). Pair dorsal jugal muscles (m1d) of buccal mass, inserting into m5, connecting to dorsal-anterior end of snout (Fig. 25). Pair m4, main dorsal tensor muscle of radula, reduced, originating in lateral region of cartilages, surrounding them ven- trally, inserting into subradular membrane (Figs. 25-26). Pair $\mathrm{m} 5$, secondary dorsal tensor muscle of radula, large and broad, covering median portions of cartilage, extending up to dorsal region; originating in posterior surface of cartilages; inserting laterally in mj (Figs. 25-26). Pair m7 absent. Pair m10d (dorsal) absent. Pair of $\mathrm{m} 10 \mathrm{v}$ connecting $\mathrm{mj}$ with ventral portion of m5 (Fig. 26). Single auxiliary muscle m10a, ventral tensor muscle of radula, originating in anterior portion of oral canal, running in middle of buccal mass, inserting into radular sac (Fig. 26). Pair of strong retractor muscles originating in most posterior portion of $\mathrm{m} 5$ (Figs. 25-27); separated in its anterior third and jointed in its posterior portion, laying above anterior portion of digestive gland. Odontophore cartilage semicircle in outline (Fig. 28). Radula rectangular, two times longer than wide; formula $63 \times 52.0 .52$ (from preserved specimen 11 mm length); $48 \times 49.0 .49$ (from preserved specimen $6 \mathrm{~mm}$ length). Radula lackinck rachidian tooth (Fig. 22); lateral plates smooth hook shaped, without denticles (Fig. 22); base of tooth enlarged (square) and concave (Fig. 23); innermost lateral tooth hook-shaped (Fig. 22); subsequent lateral plates hook-shaped, larger and more developed in center of rows (Fig. 23); outermost laterals teeth less developed (Fig. 24). Floor of Pharyngeal bulb greatly reduced, causing a slightly rotation in radula position. Absence of acid gland (Fig. 25). Esophagus sac-like tube, passing into voluminous stomach (Fig. 27). Salivary gland small and in front of digestive gland (Figs. 25-26). Ducts of salivary glands entering pharynx musculature laterally to esophagus, opening into base of pharyngeal cavity between radula and jaw plates (Figs. 25, 27); convoluted; without visible ampulla. Stomach passing ventrally into digestive gland, embedded in digestive gland until dorsal view (Fig. 26); internally, stomach with main groove from where depart others perpendiculars grooves (Fig. 27). Posteriorly, stomach passing into intestine; intestine passing in dorsal portion of digestive and hermaphrodite glands, opening laterally on body wall (Fig. 25); internally, intestine with longitudinal folds (Fig. 27). Glands: salivary, digestive, and hermaphrodite forming single aggregate (Figs. 25-26).

Egg mass (Fig. 3). Egg mass forming a spiral ribbon with enlarged border with 1.5-2 turns in counterclockwise direction, containing numerous rows of many tiny eggs; usually white; $10 \mathrm{~mm}$ of diameter. White eggs surrounded by translucent matrix; diameter of eggs about $140 \mu \mathrm{m}$. Eggs disposed in longitudinal rows; many rows per thickness; each row presents about 35 eggs with 6-9 eggs per thickness.

Material examined. Brazil: Rio Grande do Norte: Praia de Santa Rita: MZSP 97047, 11/iii/2009, V. Padula coll. [1]; Praia de Búzios: MZSP 97066, 13/iii/2009, V. Padula coll. [1]; Baia Formosa: MZSP 97067, 04/vii/2009, V. Padula coll. [1]. Pernambuco: Praia do Suape: MZSP 86140, 28/iii/2006, F. Santos [3]; MZSP 97348, 19/vii/2004, V. Padula coll. [5]. Alagoas: Morro de Caragibe: MZSP 77000, 23/xii/2010, C.M. Cunha coll. [1]. Espírito Santo: Praia dos Padres: MZSP 96421, 25/vi/2010, P. 


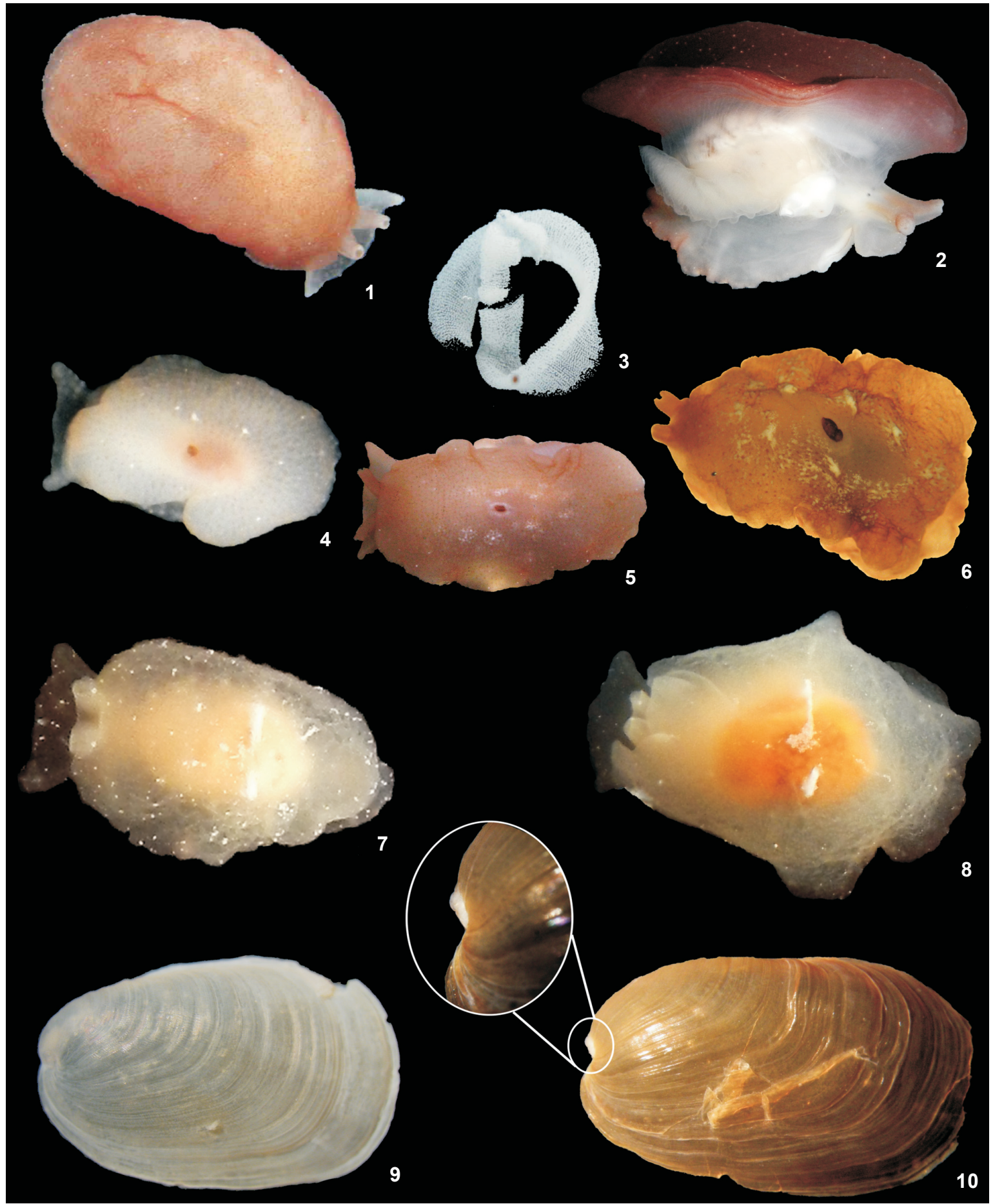

Figures 1-10. Living species of Berthella from Brazil. (1-2) Berthella agassizii; (1) dorsal view, MNRJ 30346, 23 mm long alive; (2) lateral view, MNRJ 31332, 18 mm long alive; (3) egg mass, MNRJ 30346, 10 mm of diameter; (4-6) Berthella punctata sp. nov., dorsal view; (4) MNRJ 34013, 7 mm long alive; (5) MZSP 97088, $13 \mathrm{~mm}$ long alive, photo: V. Padula; (6) MZSP115665, $9 \mathrm{~mm}$ length of preserved specimen, photo: P. Lima; (7-10) Berthella stellata; (7-8) dorsal view, MNRJ 31330; (7) $7 \mathrm{~mm}$ long alive; (8) $14 \mathrm{~mm}$ long alive; (9-10) dorsal view of the shell; (9) white, MNRJ 31246, $2.6 \mathrm{~mm}$ in length; (10) brown, MNRJ 30345, $8.8 \mathrm{~mm}$ in length. 


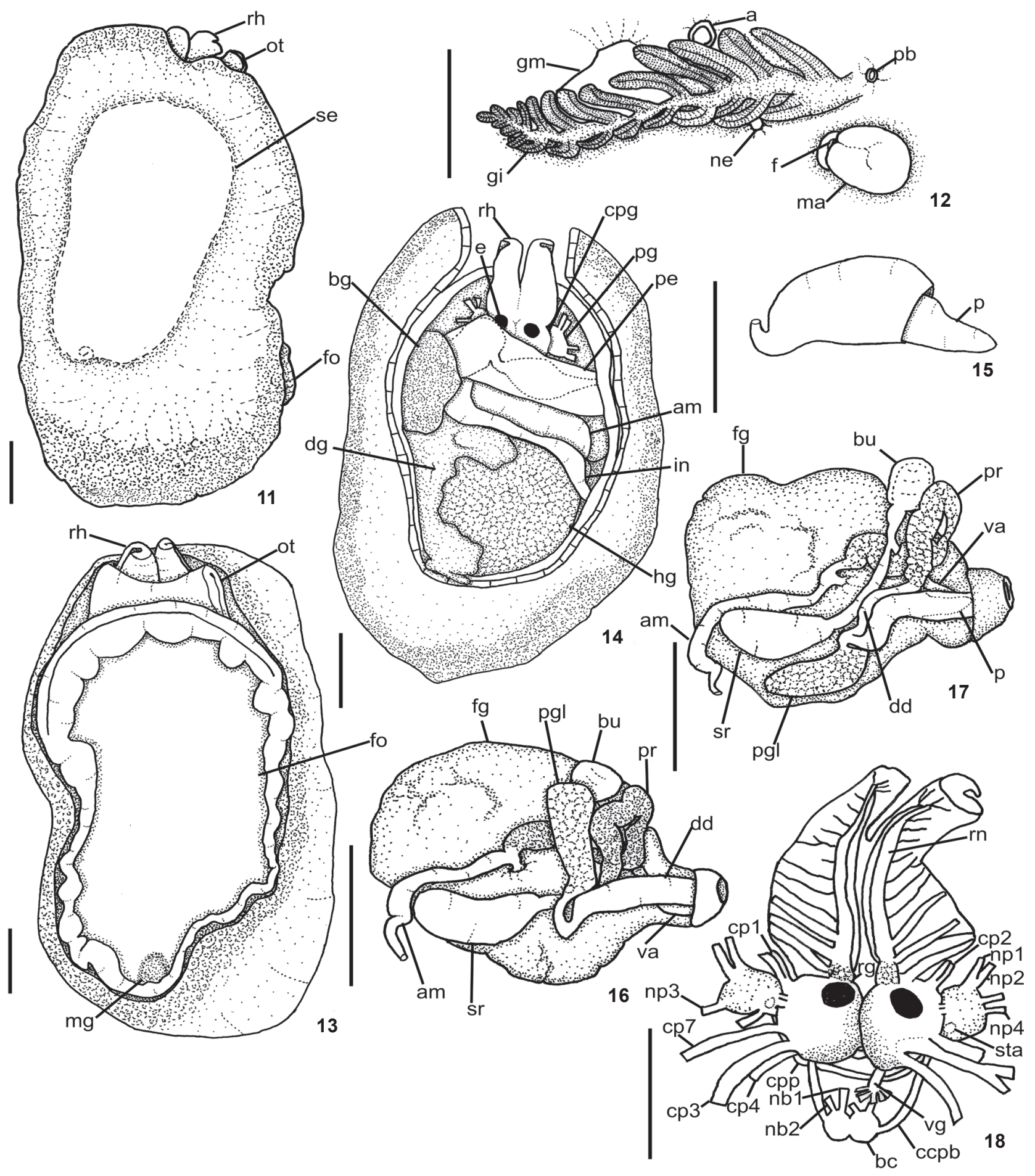

Figures 11-18. Berthella agassizii: (11) dorsal view, dotted line indicates position of shell internally, MNRJ 14983; (12) lateral view, MNRJ 14992; (13) ventral view, MNRJ 14983; (14) dorsal view, organization of internal organs, MNRJ 14998; (15-17) reproductive system, dorsal view, MNRJ 14992; (15) detail of the penis; (17) deflected; (18) central nervous system, dorsal view, MNRJ 14983. Scale bars: 11-16, 18 = $1.0 \mathrm{~mm}, 17=0.5 \mathrm{~mm}$. 

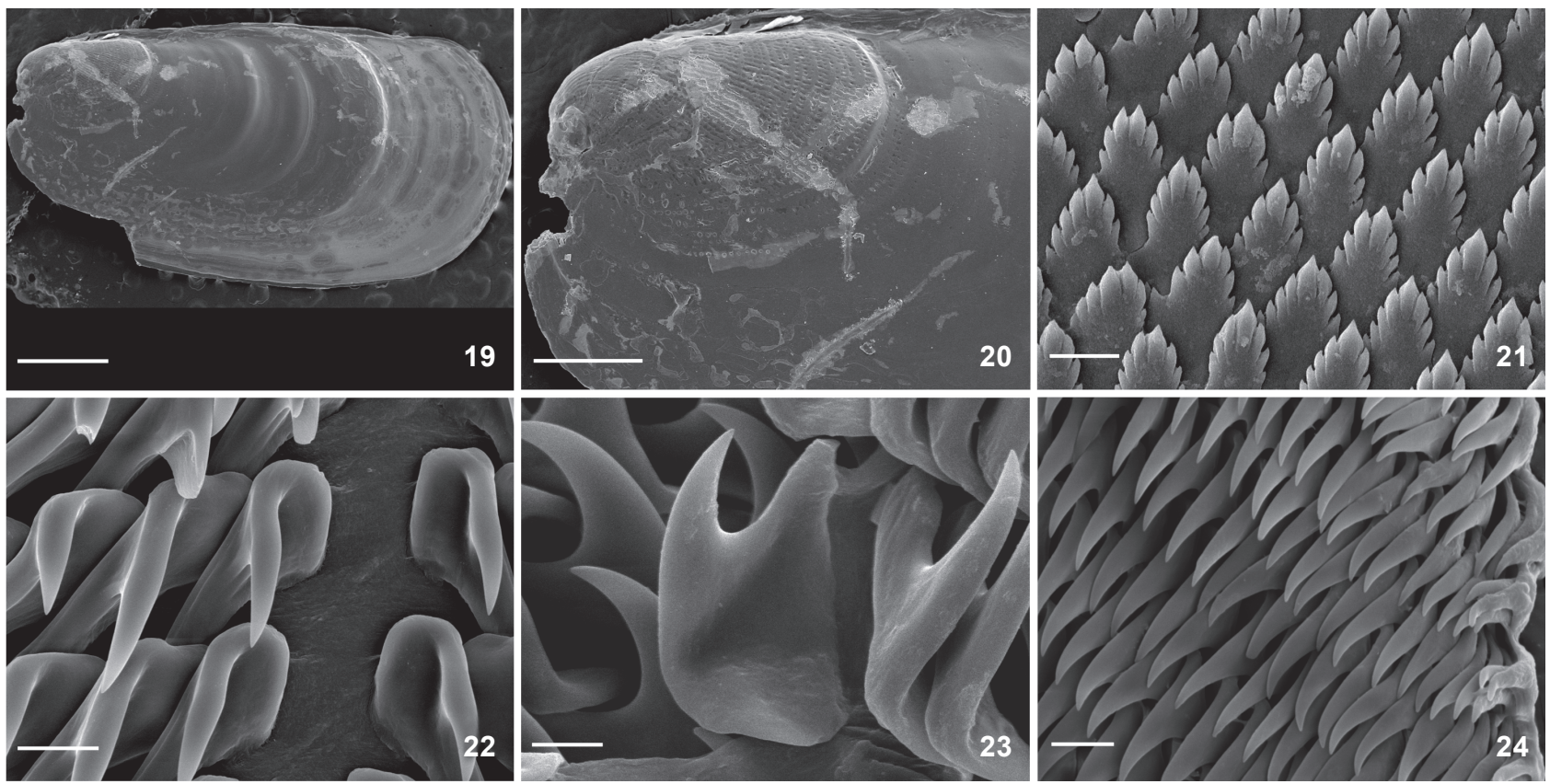

Figures 19-24. Berthella agassizii, SEM: (19-20) shell, MNRJ 14983; (20) detail near protoconch; (21) elements of jaw, MNRJ 14982; (2224) radula; (22) innermost lateral teeth, MNRJ 30346; (23) lateral teeth, MNRJ 11062; (24) outermost lateral teeth, MNRJ 14992. Scale bars: $19=1 \mathrm{~mm}, 20=500 \mu \mathrm{m}, 21-22,24=10 \mu \mathrm{m}, 23=5 \mu \mathrm{m}$.

Lima coll. [1]. Rio de Janeiro: MNRJ 14998, 14/x/2006, V. Padula coll. [1 dissected]; Cabo Frio: Praia das conchas: MNRJ 15004, 24/vii/2005, F. Santos coll. [2]; MZSP 97663, 21/ii/2006, V. Padula coll. [4]; MNRJ 14997, 24/xii/2005, V. Padula coll. [2]; MNRJ 14982, 24/vi/2005, V. Padula coll. [2; 1 dissected]; MNRJ 14992, 23/ii/2006, V. Padula coll. [1 dissected]; MNRJ 14985, 21/vi/2005, V. Padula coll. [1]; MNRJ 14983, 13/xi/2004, F. Santos coll. [3; 2 dissected]; MNRJ 14984, 25/viii/2008, V. Padula coll. [2]; MZSP 97571, 16/x/2009, V. Padula coll. [1]; MZSP 97323, 23/iv/2005, V. Padula coll. [4]; MZSP 97327, 30/iv/2005, V. Padula coll. [4]; MZSP 97508, 13/xii/2008, V. Padula coll. [2]; Praia do Peró: MZSP 25292, vii/1957, Marcus coll. [1]; Canal de Itajurú: MNRJ 31140, 10/iii/2012, J. Alvim \& P. Romano colls. [3; 1 dissected]; MZSP 97505, 18/v/2008, V. Padula coll. [2]; MZSP 97577, 10/xii/2007, V. Padula coll. [1]; MNRJ 31332, 15/iii/2013, J. Alvim, M. Fernandes \& T. Belmonte colls. [2]; Ilha do Papagaio: MZSP 97469, iv/2006, V. Padula coll. [2]; MZSP 97564, 23/iv/2009, V. Padula coll. [1]; Arraial do Cabo: Prainha: MNRJ 11062, 18/iii/2003, F. Santos coll. [1 dissected]. São Paulo: São Sebastião: MZSP 25291, Marcus coll. [1]; MZSP 86009, 21/ ix/2005, C.M. Cunha coll. [1]; Ilha Bela: MZSP 41802, 07/v/ 2004, C.M. Cunha coll. [1]. Santa Catarina: Itapema: Praia do canto: MNRJ 30346, 03/i/2012, J. Alvim coll. [1 dissected].

Specimen records. Pacific Ocean: Mexico: Baja California (Gosliner \& Bertsch 1988); Atlantic Ocean: Belize (Valdés et al. 2006); Bahamas: Abaco (RedFern 2001); Colombia: Santa Marta (Ev. Marcus 1976); Curaçao (Engel 1927, Ev. Marcus \& Er. Marcus
1963, Er. Marcus \& Ev. Marcus 1970); Bermuda: Hungry Bay, Gravelly Bay (Clarck 1984); Brazil: Rio Grande do Norte (present study); Pernambuco (present study); Alagoas: Maceió (GARCía et al. 2008), Riacho doce (MacFarland 1909); Espírito Santo (present study); Rio de Janeiro: Búzios (García et al. 2008), Cabo Frio (Ev. Marcus \& Er. Marcus 1964, Er. Marcus 1958), Arraial do Cabo (present estudy); São Paulo: Ilha de São Sebastião (ER. MARcus 1955); Santa Catarina: Itapema (present study).

Distribution. Pacific Ocean: Mexico; Atlantic Ocean: Caribbean Sea to Brazil (Rio Grande do Norte to Santa Catarina).

Remarks. Berthella agassizii was originally described from Alagoas, Brazil, and was subsequently cited in many catalogues from Brazil and the Caribbean (RIos 1994, 2009, Valdés et al. 2006, García et al. 2008). In Brazil, B. agassizii and B. stellata are sympatric, which also happens in the Caribbean Sea (Gosliner \& BERTSCH 1988). Living specimens of B. agassizii are easily recognized by their translucent pale pink to reddish-pink body surface, with scattered opaque white spots (Figs. 1-2); besides that, they present a black pigment in the seminal receptacle, a diagnostic feature.

CLARK (1984) suggested that B. agassizii is similar to Pleurobranchopsis aurantiaca Verrill, 1900 due to similarities in their descriptions, except for the absence of a shell in $P$. aurantiaca. CLARK (1984) noted that the shell is highly transparent and easily overlooked in living animals, which could explain why Verrill (1900) established the shell-less Pleurobranchopsis. However, Clark (1984) did not synonymize 


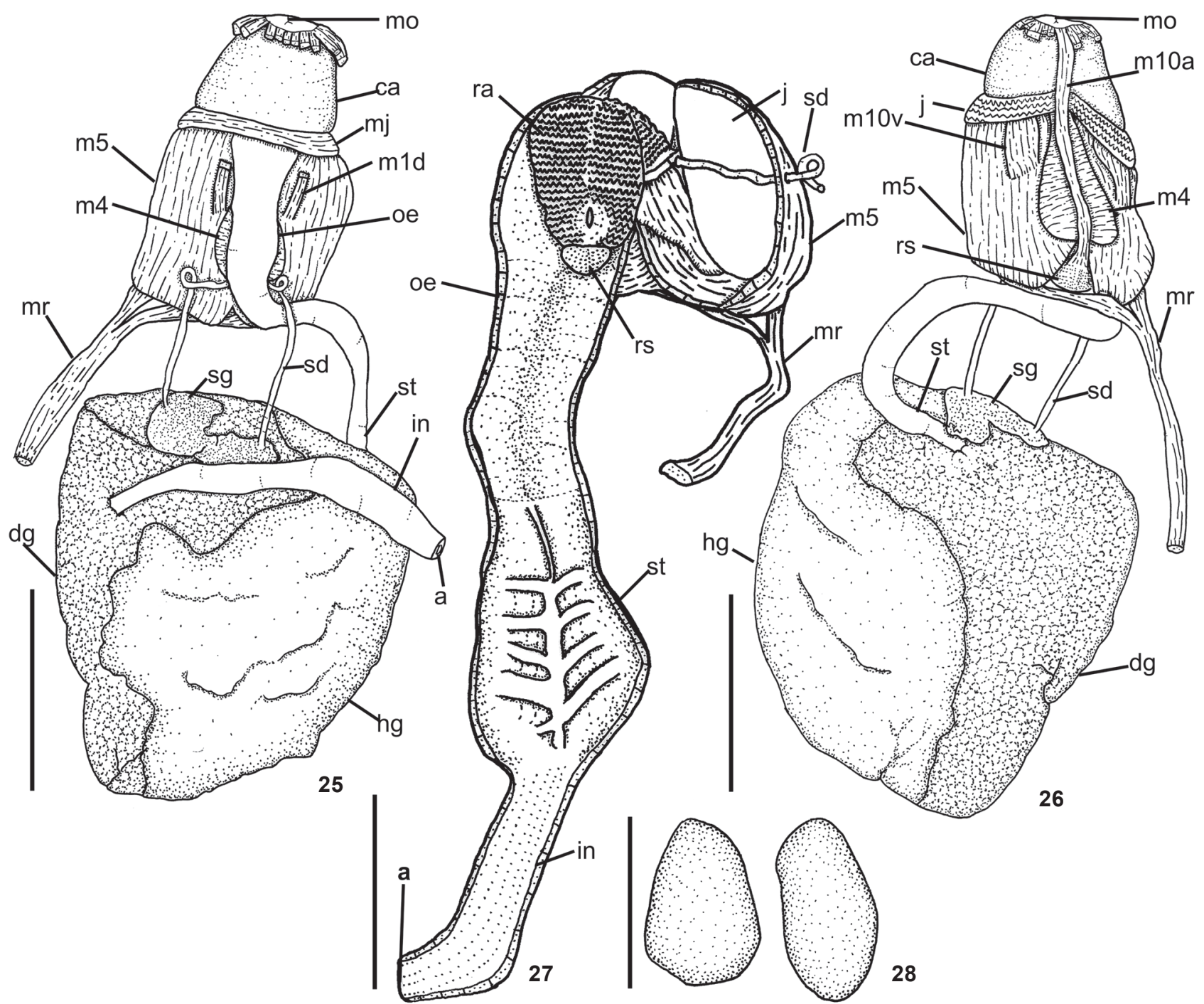

Figures 25-28. Berthella agassizii, digestive system. (25) dorsal view, MNRJ 31140; (26) ventral view,MNRJ 31140; (27) foregut sectioned longitudinally from ventral side,MNRJ 14983; (28) odontophoral cartilages, MNRJ 14983. Scale bars: 1.0 mm.

these two species because Verrill's description lacked sufficient diagnostic characteristics to allow synonymy in the absence of the holotype of $P$. aurantica; thus, he preferred to consider $P$. aurantica as nomen dubium.

Besides that, $P$. aurantiaca has a problematic nomenclatural and taxonomic history. THIELE (1931) inferred that Pleurobranchopsis was a subgenus of Pleurobranchus, thus the new name combination Pleurobranchus aurantiaca (Verrill, 1900) became a homonymy of Pleurobranchus aurantiacus Risso, 1818, species described from the Mediterranean Sea. To solve this nomenclatural problem, THIELE (1931) created a new name for species from the Bermudas, Pleurobranchus verrilli Thiele, 1931. Berthella agassizii and $P$. verrilli are well established as dis- tinct species, however we would like to emphasize the differences between these two species. In spite of Verrill's brief description, there are some characteristics that clearly distinguish these two species: in $P$. verrilli the gill is attached laterally along its entire length, while in B. agassizii we find 5-6 pinnae that are free from the body wall (Fig. 12); the mantle, gill and foot are orange in $P$. verrilli, whereas in $B$. agassizii the mantle is pink, the foot is white, and the gill with the upper pinnae are rosy (Figs. 1-2); P. verrilli is relatively larger, between $32 \mathrm{~mm}$ to 36 $\mathrm{mm}$, whereas $B$. agassizii measures $7 \mathrm{~mm}$ to $23 \mathrm{~mm}$; and the possible egg mass find by VerRILL (1900) had numerous bright orange eggs in many rows, while the egg masses of B. agassizii are white (Fig. 3) (BANDEL 1976, present study). 


\section{Berthella punctata sp. nov.}

Figs. 4-6, 29-52

Berthella sp.: Valdés et al., 2006: 110; PAdula et al., 2012: 3.

Diagnosis. Living specimens translucent white to brown, passing through rosy (Figs. 4-6); one dark pink spot, almost brown, in middle of mantle, surrounded by white patches (Figs. 4-6). Anal opening lying approximately above $5^{\circ}$ pinnae (Fig. 31). Elements of jaw without denticles (Figs. 45-46). Presence of jugal muscle $\mathrm{m} 1 \mathrm{vb}$, originating into dorsal portion of mouth, inserting into ventral portion of m5 (Figs. 49-51). Voluminous stomach covering entire dorsal portion of pharyngeal bulb (Figs. 49-50). Ampulla very thick and elongated, 8-17 times thicker than deferent duct (Figs. 34-35); deferent duct curved, but not convoluted (Figs. 34-35).

Description. External morphology (Figs. 4-6, 29-31). Living specimens translucent white to brown, passing through rosy (Figs. 4-6); one dark pink spot, almost brown, in middle of mantle, which are surrounded by white patches (Figs. 4-6); rhinophores, oral veil, gill and foot of same pattern color as mantle. Living specimens up to $13 \mathrm{~mm}$ in length; length of mature preserved specimens $6-9 \mathrm{~mm}$; width $4 \mathrm{~mm}$; length of foot 5-6 mm; width of foot $2 \mathrm{~mm}$. Body oval and oblong. Mantle covered foot entirely. Mantle surface smooth in its middle; honeycomb appearance in mantle edge, larger honeycomb appearance in the posterior portion than anterior portion. Oral veil thin and trapezoidal connected with the head region (Fig. 30); laterally, oral tentacles with deep notch, corresponding almost its length. Rhinophores rolled joined at their bases, up to two-thirds of its length. Gill exposed laterally (Fig. 31); $2 / 5$ length of body; main rachis smooth, without tubercles; alternate pinnae; simple pinnae; 17-22 pinnae; 7-13 pinnae free from body wall, attached by branchial membrane. Anal opening lying approximately above $5^{\circ}$ pinnae (Fig. 31 ). Prebranchial pore opening beside main rachis. Genital aperture surrounded by collar (Fig. 31). Penis retractable. Foot slightly pointed at posterior end with elongated metapodial gland; metapodial gland 0.3 times foot length; anteriorly bilabiated, upper lip notched, smaller than lower one. Eyes localized just behind rhinophores.

Mantle (Figs. 39-42). Mantle, rhinophores and oral veil covered by stellate spicules (Fig. 42). Two types of spicules in mantle: linear (length: 90-180 $\mu \mathrm{m}$ (Fig. 39), few spicules with 440-450 $\mu \mathrm{m}$ (Fig. 40); thickness: $10 \mu \mathrm{m}$ ) and stellate with fourfive rays irregular and in different plans (ray length: $30 \mu \mathrm{m}$; ray thickness: $10 \mu \mathrm{m}$ ) (Figs. 41-42). Rod-like spicules calcareous; stellate spicules partially calcareous, but not entirely formed by calcium carbonate because in sodium hypochlorite they partially dissolve, it is also composed of an organic matrix not identified.

Shell (Figs. 43-44). Translucent white, with light golden tones in some parts of shell, visible according to incidence of light; subquadrangular in outline; slightly convex profile; ap- proximately two times longer than wide. Length $5.9 \mathrm{~mm}$, width $2.9 \mathrm{~mm}$ (in preserved specimen with $8 \mathrm{~mm}$ in length); and, length: $6.8 \mathrm{~mm}$, width $2.9 \mathrm{~mm}$ (in preserved specimen with 9 $\mathrm{mm}$ in length). Spire with 1.5 whorls. Protoconch smooth (Fig. 44). Lines of growth distinct; immediately after protoconch, with longitudinal sculptures transverse to lines of growth (Fig. 44); shell smooth after the last line of growth. Shell above heart, on right side of blood gland. Shell covering almost all visceral mass.

Circulatory system (Fig. 32). Circulatory system of $B$. punctata sp. nov. identical to the B. agassizii as described above. Reproductive system (Figs. 33-37). Ampulla very thick and elongated, eight to 17 times thicker than deferent duct (Figs. 33-35); curved, but not convoluted (Figs. 34-35). Spermoviduct branching into two ducts, shorter and wider oviduct leading to female gland mass, other duct leading to prostate (Figs. 34-35). Deferent duct glandular in 63\% to 79\% its length (Figs. 34-35). Prostatic portion of deferent duct folds once to twice; near its distal end it joins with elongated and curved penial gland and narrows near into elongated penis. Penial gland four to five times thicker than deferent duct (Figs. 34-35). Penis (Fig. 39) (in preserved specimen with $8 \mathrm{~mm}$ length: length $0.94 \mathrm{~mm}$; width $0.3 \mathrm{~mm}$ ); (in preserved specimen with $9 \mathrm{~mm}$ length: length $0.95 \mathrm{~mm}$; width $0.4 \mathrm{~mm}$ ); completely contractible. Bursa copulatrix and seminal receptacle join vaginal duct in its proximal portion (Figs. 34-35, 37). Elongated to rounded bursa copulatrix (Figs. 34-35, 37). Seminal receptacle stalked and bean-shaped; twice or same volume than bursa copulatrix (Fig. 37). Vagina not convoluted; about same diameter of deferent duct (Figs. 34-35). Vaginal opening immediately ventral to penis. Genital aperture surrounded by fold.

Nervous system (Fig. 38). Nervous system of B. punctata sp. nov. very similar to $B$. agassizii as described above, with the following exceptions: cp7 absent in cerebro-pleural ganglia. Nerves leaving buccal ganglia: nb1 inserting into esophagus; nb2 inserting into salivary ducts; nb3 leading to m5; connective cerebro-pleural-buccal shortly after nb3. Connective cerebro-pleural-pedal (ccpp) extremely short and it can only be seen after carefully dissecting.

Digestive system (Figs. 45-52). Digestive system of $B$. punctata sp. nov. very similar to B. agassizii as described above, with the following exceptions: Each jaw plate showing alternate rows formed by elongated elements without denticles with slight cruciform lateral expansion (18 elements transversal, in preserved specimen measuring $8 \mathrm{~mm}$ in length) (Figs. 45-46); anterior elements worn. Pair of m1va originating in posterior portion of oral canal (Fig. 51), running in the middle of buccal mass and inserting near radular sac. Pair of m1vb originating into dorsal portion of mouth and inserting into ventral portion of m5 (Fig. 50). Single auxiliary muscle m10a absent. Pair of strong retractor muscles originating in most posterior portion of $\mathrm{m} 5$ (Fig. 51); separated in middle of its anterior length and jointed in its posterior portion, laying above anterior por- 


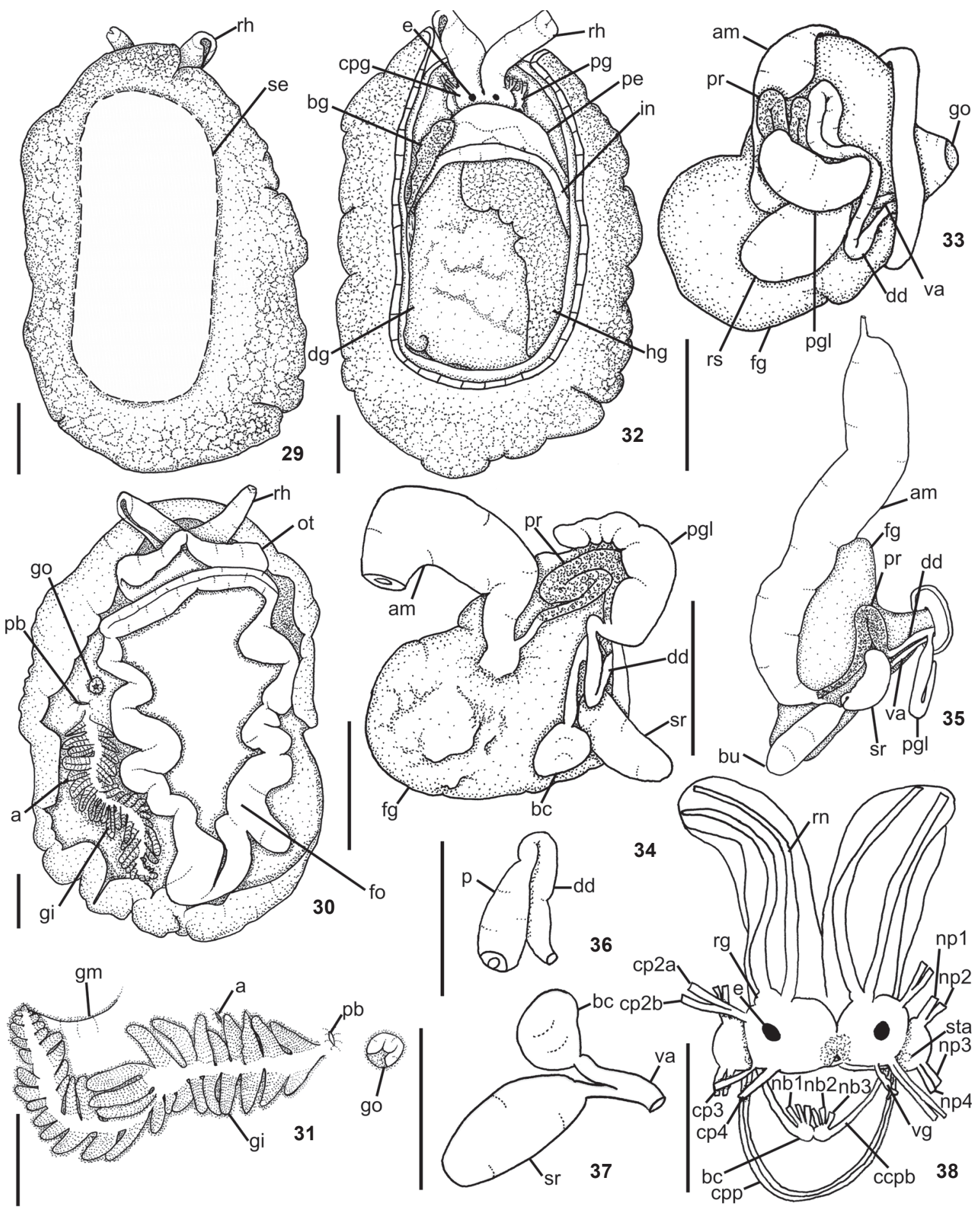

Figures 29-38. Berthella punctata sp. nov. (29) whole dorsal view, dotted line indicates position of shell internally, MZSP 97088; (30) ventral view, MZSP 97088; (31) detail of lateral view, MZSP 97088; (32) Dorsal view, organization of internal organs, MZSP 97088; (3337) reproductive system, dorsal view; (33-34) MZSP 115665; (34) deflected; (35) deflected MZSP 97088; (36) penial papilla, MZSP 115665; (37) detail of the connection between bursa copulatrix and seminal receptacle, MZSP 115665; (38) central nervous system, dorsal view, MZSP 97088. Scale bars: $1.0 \mathrm{~mm}$. 



Figures 39-42. Berthella punctata sp. nov., spicules, MZSP 115665 (39-40) linear spicules into the mantle, black arrow indicates spicule; (41-42) stellate; (41) spicules into the mantle, white arrow indicates spicule; (42) spicules into the rhinophores. Scale bar: $100 \mu \mathrm{m}$. tion of digestive gland. Radula rectangular; formula $72 \times 38.0 .38$ (from preserved specimen $8 \mathrm{~mm}$ length); $65 \times 47.0 .47$ (from preserved specimen $9 \mathrm{~mm}$ length). Radula lacking a rachidian tooth; innermost lateral tooth hook-shaped; subsequent lateral plates hook-shaped, larger and more developed in center of rows, base of tooth not enlarged (Fig. 47); outermost laterals teeth less developed (Fig. 48). Esophagus internally with longitudinal folds (Fig. 52). Salivary gland small and in front of digestive gland (Fig. 49). Ducts of salivary glands entering pharynx musculature laterally to esophagus, opening into base of pharyngeal cavity between radula and jaw plates (Fig. 50); convoluted; without visible ampulla. Voluminous stomach covering all dorsal portion of pharyngeal bulb (Figs. 49-50); thin lines internally (Fig. 52); stomach passing dorsally into the digestive gland and surrounds the digestive gland (Figs. 49-50). Posteriorly, stomach passes into intestine (Fig. 49); intestine long and thin and embedded in dorsal portion of the digestive and hermaphrodite glands and, opening laterally in body (Fig. 49); internally, intestine with longitudinal folds (Fig. 52).

Type material. Holotype MNRJ 34013, 12/x/2014, tide pool, J. Alvim coll. Paratypes: MZSP 115665, off Espírito Santo, Ilha da Trindade, Praia do Príncipe-Pedra da Garoupa $\left(20^{\circ} 31^{\prime} 35,58^{\prime \prime} \mathrm{S} / 29^{\circ} 18^{\prime} 94,38^{\prime \prime} \mathrm{W}\right), 16 / \mathrm{vii} / 2013,8 \mathrm{~m}$ depth, D. Abbate \& P. Lima colls. [1 dissected]; MZSP 97088, Alagoas, Saco da Pedra 11/i/2008, V. Padula coll. [1 dissected].

Type locality. Guarapari $\left(20^{\circ} 39^{\prime} 35^{\prime \prime} \mathrm{S} / 40^{\circ} 28^{\prime} 31^{\prime \prime} \mathrm{W}\right)$, Espírito Santo, Brazil.

Specimen records. Puerto Rico (VAldés et al. 2006); Brazil: Alagoas, Saco de Pedra (Padula et al. 2012); Espírito Santo: Ilha da Trindade and Guarapari (present study).

Distribution. Caribbean Sea to Brazil.

Etymology. punctata, from Latin "punctatus" means dotted. The name refers to the dark pink spot or almost brown in middle of mantle.

Remarks. Berthella punctata sp. nov. fits perfectly in Berthella, presenting all general characteristics of the genus, including the ovate and large shell (Figs. 43-44); elliptical or convex body (Figs. 4-6); generally smooth gill rachis; hookshaped radular teeth (Figs. 47-48); smooth jaw elements (Figs. 45-46).

Berthella punctata sp. nov. is clearly distinguished from most species of the genus by its external morphology and color, including the two species that occur in Brazil, B. stellata and B. agassizi. The most similar species to $B$. punctata sp. nov. are Berthella africana (Pruvot-Fol, 1953) and B. tamiu, mainly due to the pigmented spot in the middle of the mantle.

Berthella punctata sp. nov. has some similarities with $B$. africana from Morocco, mainly due to the beige to brown coloration with a dark spot in the middle of the mantle. PRuvotFol (1953) made a mistake in the description of B. africana that was clarified some years later by GANTÈs (1956): the plates that Gantès sent to Pruvot-Fol represented B. africana (Pruvot-Fol, 

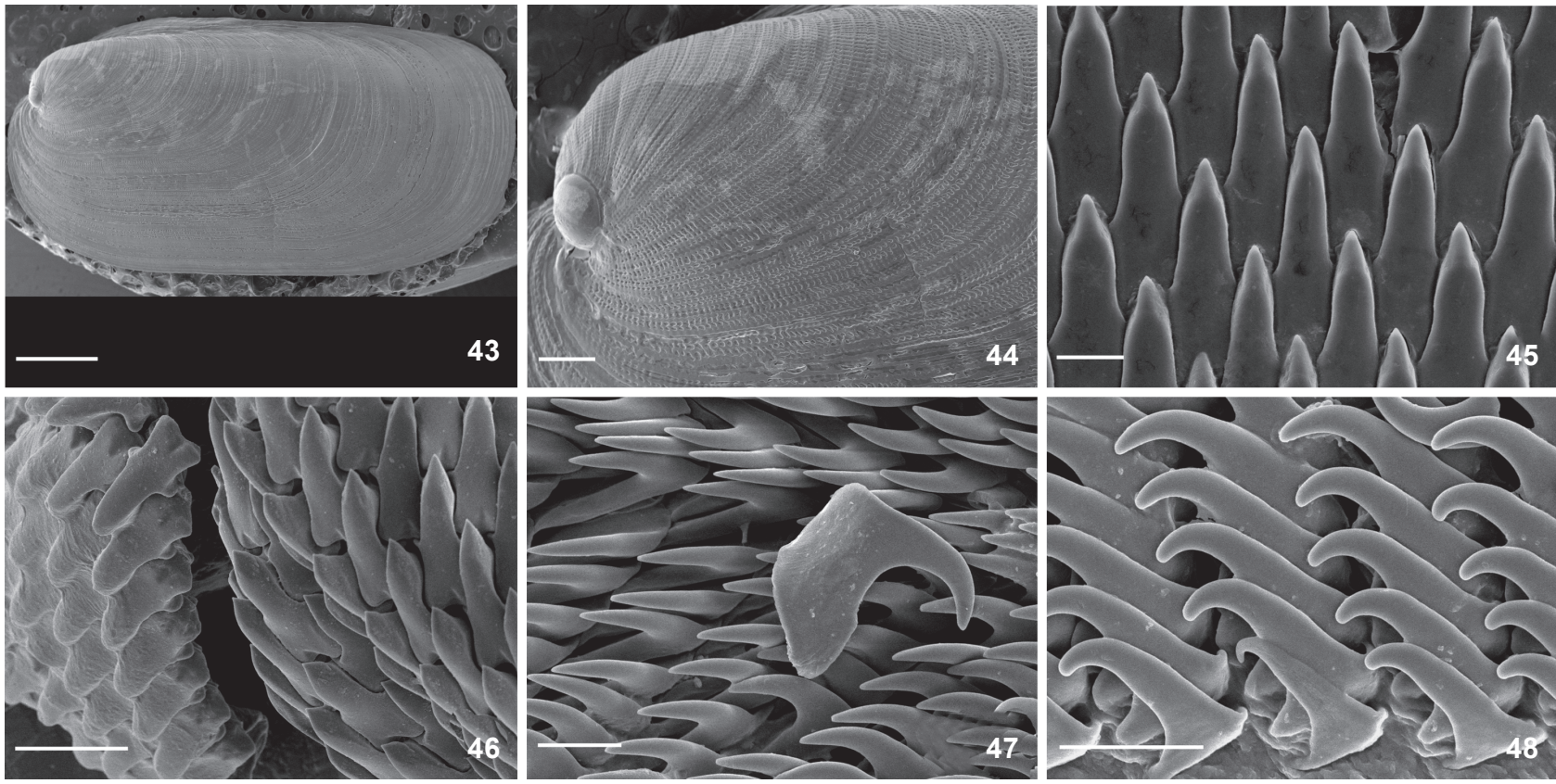

Figures 43-48. Berthella punctata sp. nov., SEM. (43-44) shell, MZSP 97088; (44) detail near protoconch; (45) elements of jaw, MZSP 97088; (46) lateral view of the elements of jaw, MZSP 115665; (47-48) radula, MNRJ 115665; (47) lateral teeth; (48) outermost lateral teeth. Scale bars: $43=1.0 \mathrm{~mm}, 44=200 \mu \mathrm{m}, 45,47-48=20 \mu \mathrm{m}, 46=50 \mu \mathrm{m}$.

1953: pl. 49-51), but the description made by PRUvOT-Fol (1953) for B. africana actually corresponds to Berthella aurantiaca (Risso, 1818). Berthella africana was poorly described and the type is probably lost, but based on the redescription of this species by GANTÈs (1956), it can be distinguished from B. punctata sp. nov. by the absence of denticles on the elements of the jaw in $B$. punctata sp. nov. (Fig. 45-46), once B. africana was described with two or three denticles. Recently, Ortea et al. (2012) concluded that Berthella canariensis Cervera, Gosliner, GarciaGomez \& Ortea, 2000 is a junior synonym of B. africana. Considering that, assuming that $B$. canariensis was adequately described, B. punctata sp. nov. differs from it in the proportion of the bursa copulatrix and the seminal receptacle, and the position of the junction in relation to the vaginal duct, the shape of the penial gland, the proportion of the ampulla, the prostatic portion of the deferent duct, not as convoluted as in $B$. africana/B. canariensis, and the proportion of the shell in relation to the body. Thus, we conclude that B. africana and $B$. punctata sp. nov. are distinct species.

Berthella punctata sp. nov. closely resembles B. tamiu from Mexico. These similarities are: brownish mantle, number of pinnae in the gill (B. punctata sp. nov.: 21 ; B. tamiu: 26), unicuspidate elements of jaw (without denticles in relation to the main cuspid), radula formulae (B. punctata sp. nov.: $72 \times$ 38.0.38; B. tamiu: $72 \times 50.0 .50)$, hook-shaped teeth without any denticles, genital opening with a ring-fold without flaps and slender penis. The unique difference according to the de- scription made by Ev. MARCus (1984) is that B. tamiu has a small reflective circlet in the middle of the jaw elements (Fig. 57), which was not observed in B. punctata sp. nov. (Figs. 45-46). Recently, four microscope slides of the syntypes of $B$. tamiu were found (MZSP 121400, Figs. 53-60), including the cerebropleural complex (Fig. 53), transversal cuts of the mantle (Figs. 54-55), radula and jaw platelets (Figs. 56-57) and penis (Figs. 58-60), which make the comparison between these two species possible. There are sparse linear spicules in the mantle of the syntypes as well as in the mantle B. punctata sp. nov. (Figs. $39-40,55)$; the small reflective circlet in the middle of the jaw elements mentioned by Ev. Marcus (1984) is not a preservation artifact (Fig. 57), since it can be observed all over the jaw. In contrast, even when we examined the elements of $B$. punctata sp. nov. in profile (Fig. 46) the small reflective circlet was never observed, the elements are always superficially smooth; the penis of $B$. tamiu is relatively larger (1533 $\mu \mathrm{m}$ in length) (Figs. 59-60) than that of $B$. punctata sp. nov. (940-950 $\mu \mathrm{m}$ in length) (Fig. 36); the deferent duct of $B$. tamiu is highly convoluted (Fig. 59), while in B. punctata sp. nov. it is not (Figs. 34-35). Slides with the complete reproductive system of the syntypes of B. tamiu were not found. B. tamiu is undoubtedly the most similar species to $B$. punctata sp. nov., however based on the differences in the jaw elements, penis, deferent duct and bathymetric distribution, B. tamiu occurs at great depths (146-265 $\mathrm{m})$, while $B$. punctata sp. nov. is found in tide pool to a $8 \mathrm{~m}$ depth, we prefer to maintain these two species as distinct. 


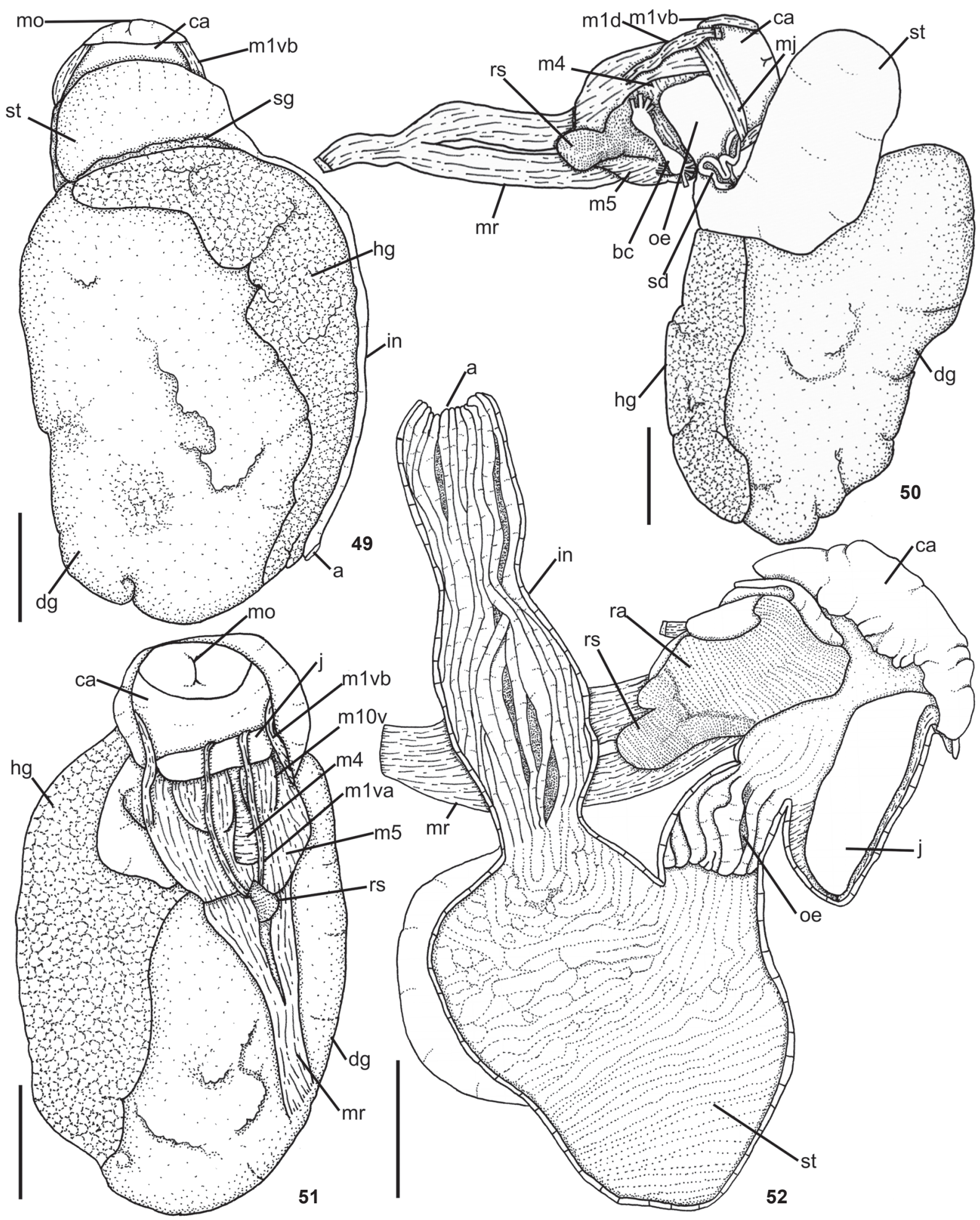

Figures 49-52. Berthella punctata sp. nov., digestive system, MZSP 97088. (49-50) dorsal view; (50) stomach deflected; (51) ventral view; (52) foregut sectioned longitudinally from ventral side. Scale bars: $1.0 \mathrm{~mm}$. 

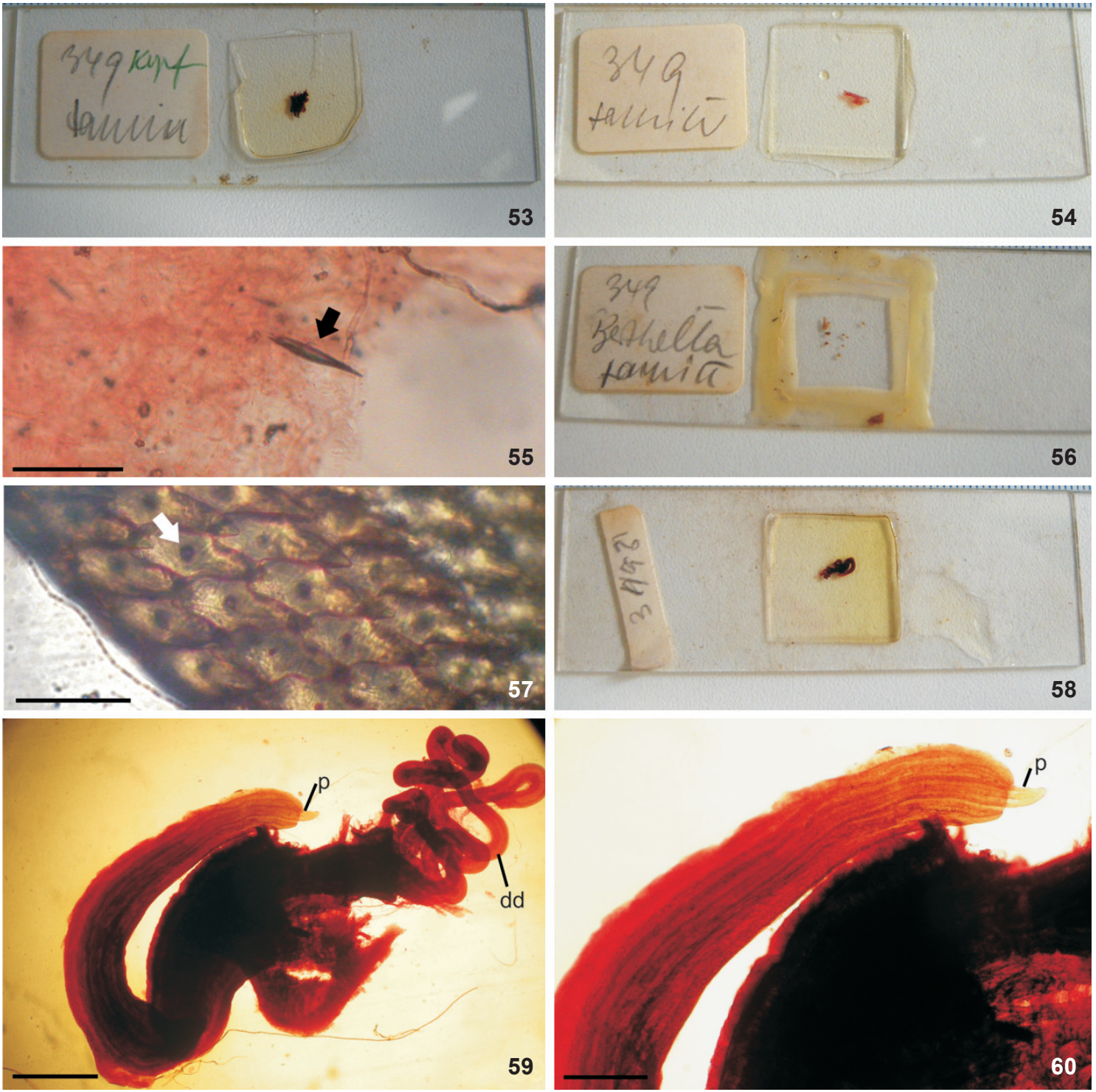

Figures 53-60. Berthella tamiu, syntypes microscopic slides, MZSP 121400. (53) cerebro-pleural complex; (54-55) transverse cut of mantle; (55) linear spicule, black arrow indicates spicule; (56) radula and jaw plates; (57) detail of jaw elements, white arrow indicates small reflective circlet; (58-60) region near penis; (60) detail of penial papillae. Scale bars: $55=200 \mu \mathrm{m}, 57=100 \mu \mathrm{m}, 59=2.0 \mathrm{~mm}, 60=1.0 \mathrm{~mm}$.

The color pattern of $B$. punctata sp. nov. is very similar to Pleurobranchus caledonicus Risbec, 1928 from New Caledonia, which probably belongs to Berthella; both species have a brownish mantle, with a dark spot in the middle of the mantle surrounded by a light ring (Figs. 4-6). However, this dark spot in the middle of the dorsum is only a dark blotch in B. punctata sp. nov., while Risbec (1928) described it as a hole in $P$. caledonicus. Gary Cobb (pers. comm., 16 January 2014) found a specimen from Queensland, Australia, with the same features of $P$. caledonicus, except for the mark on the dorsum, which stands out for its coloration but is not a hole. It is possible that RISBEC (1928) misinterpreted this dark spot in the middle of the dorsum as being a hole. Some differences between $B$. punctata sp. nov. and $P$. caledonicus are as follows: first, $B$. punctata sp. nov. (up to $24 \mathrm{~mm}$ in length) is smaller than $P$. caledonicus (up to $50 \mathrm{~mm}$ in length); second, there is a difference in the size of shell. The shell of B. punctata sp. nov. is 5.9 $\mathrm{mm}$ in length in a $8 \mathrm{~mm}$ long preserved specimen, while the shell of $P$. caledonicus alone is $18 \mathrm{~mm}$ in length (RIsBEC (1928) did not mention the size of the he specimen analyzed); third, 
the jaw elements of $B$. punctata sp. nov. lack denticles (one cusp) (Figs. 45-46), while Risbec (1928: fig. 68) described the jaw elements of $P$. caledonicus as having one or two cusps; fourth, the radular formulae differ in both species (B. punctata sp. nov. $72 \times 38.0 .38$, in a $8 \mathrm{~mm}$ long preserved specimen; P. caledonicus $130 \times 150.0 .150)$. Additionally, RisBec (1928) mentioned the presence of a mucus gland on the left side of the pharyngeal bulb near the mouth of $P$. caledonicus, which was not observed in B. punctata sp. nov. A future study of specimens of $P$. caledonicus from New Caledonia is necessary to elucidate the correct generic allocation of $P$. caledonicus.

VALDÉs et al. (2006) illustrated a morphotype named as Berthella sp. from Puerto Rico that closely resembles $B$. punctata sp. nov. in the external morphology and coloration. A detailed comparison between specimens from Brazil and Puerto Rico is not possible because there is no data available on the internal anatomy in VALDÉs et al. (2006).

\section{Berthella stellata (Risso, 1826) Figs. 7-10, 61-85}

Pleurobranchus stellatus Risso, 1826: 41; Mazzarelli, 1891: 73, figs. 1-5. Pleurobranchus pellucidus Pease, 1860: 24; Risbec, 1928: 63. Synonymized by GosLINER \& BERTSCH (1988).

Bouvieria stellata: Vayssière, 1898: 302.

Berthella stellata: Pruvot-Fol, 1954: 223; Thompson, 1981: 74, fig. 4; 1985: 225, fig. 2; Gosliner \& Bertsch, 1988: 50, figs. 712; Redfern, 2001: 168, pl. 117, fig. 293A-293B; pl. 72: fig. 693C; 2013: 296, figs. 814A-E; García et al., 2002: 50; Valdés et al., 2006: 110; García et al., 2008: 88; Rios, 2009: 417.

Berthella pellucidus: Thompson, 1970: 188, fig. 8.

Berthella pellucida: Kay, 1979: 443; Willan, 1984: 40, figs. 6, 7, 17, 18, 29, 37-39, 44.

Berthella tupala Er. Marcus, 1957: 416, figs, 58-69; Er. Marcus, 1958: 57; Ev. Marcus \& Er. Marcus, 1964: 198; 1967: 43, fig. 52; Er. Marcus \& Ev. Marcus, 1970: 54, fig. 102; Bertsch, 1975: 124, figs. 1-7; Ev. Marcus, 1984: 53, figs. 17-19; Rios, 1994: 206. Synonymized by GosLINER \& BERTSCH (1988).

Berthella postrema Burn, 1962: 140, figs. 1b, 2b, 4; pl. 1: fig. 2; pl. 2: figs. 3-4. Synonymized by Gosliner \& BerTsch (1988).

Berthinellops serenitas Burn, 1962: 143, figs. 1d, 2d, 5; figs. 1d, 2d, 5; pl. 1: fig. 4; pl. 2: figs. 5-6. Synonymized by SABELLi et al. (1990).

Berthella stellata albocrossata Heller \& Thompson, 1983: 328, figs. 5A-5C. Synonymized by Gosliner \& BerTsch (1988).

Type material. Type presumed lost (fide Arnaud 1978).

Type locality. Nice, Mediterranean Sea.

Description. External morphology (Figs. 7-8, 61-64). Living specimens translucent white with opaque white marks, more concentrated in middle of mantle, sometimes forming one cruces (Figs. 7-8); rhinophores, oral veil, gill and foot translucent white (Figs. 7-8). Living specimens up to $18 \mathrm{~mm}$ in length; length of preserved specimens 3-9 mm; width 2-7 $\mathrm{mm}$; length of foot 3-6 $\mathrm{mm}$; width of foot 1-3 mm. Body oval and oblong. Mantle cov- ered foot entirely. Mantle surface ranges from smooth, in juveniles, to a rough appearance. Oral veil broad and trapezoidal connected with head region (Figs. 62-63); laterally, oral tentacles with deep notch, corresponding almost its length (Fig. 63). Rhinophores rolled joined at their bases, up to $1 / 4$ of its length. Gill exposed laterally (Figs. 63-64); $1 / 2$ to $1 / 3$ length of body; main rachis smooth, without tubercles; alternate pinnae; simple pinnae; 7-11 pinnae; 3-6 pinnae free from body wall, attached by branchial membrane. Anal opening lying approximately above $3^{\circ}-4^{\circ}$ pinnae (Fig. 64). Pre-branchial pore opening beside main rachis, slightly above genital pore (Fig. 64). Genital aperture surrounded by collar (Fig. 64). Penis conical and retractable (Fig. 66). Foot slightly pointed at posterior end with metapodial gland (Fig. 62); metapodial gland 0.2 times foot length; anteriorly bilabiated, upper lip notched, smaller than lower one. Eyes localized just behind rhinophores.

Mantle (Figs. 68-70). Two types of spicules in mantle: linear, rod-like (length: $28 \mu \mathrm{m}$; thickness: $2.47 \mu \mathrm{m}$ ) (Fig. 68) and stellate with four-six rays irregular and in same plane or direct towards different plans (ray length: 2.88-20.18 $\mu \mathrm{m}$; ray thickness: 1.44-4.32 $\mu \mathrm{m}$ ) (Figs. 69-70). Rod-like spicules calcareous; stellate spicules partially calcareous, but not entirely formed by calcium carbonate because in sodium hypochlorite they partially dissolve, it is also composed of an organic matrix not identified.

Shell (Figs. 9-10, 71-72). Two color types of shells were observed. First type, in small specimens up to $9 \mathrm{~mm}$ long alive, white and very fragile (Fig. 9); subquadrangular; covers all over dorsum; approximately two times longer than wide; length $3.2 \mathrm{~mm}$, width $1.6 \mathrm{~mm}$ (in preserved specimen with $4 \mathrm{~mm}$ in length); and, length $2 \mathrm{~mm}$, width $1.7 \mathrm{~mm}$ (in preserved specimen with $3.5 \mathrm{~mm}$ in length). Second type brown with first whorl translucent white (Fig. 10), not fragile as first type; convex, subquadrangular; covers approximately $70 \%$ of mantle; approximately two times longer than wide; length $5.7 \mathrm{~mm}$, width $3.6 \mathrm{~mm}$ (with $16 \mathrm{~mm}$ long alive); and, length $8.8 \mathrm{~mm}$, width $5.3 \mathrm{~mm}$ (in with $18 \mathrm{~mm}$ long alive). Spire with 1.5-1.7 whorls (Fig. 71). Protoconch smooth (Fig. 72). Lines of growth distinct; immediately after protoconch, with longitudinal sculptures transverse to lines of growth (Fig. 72); anterior portion of last whorl only lines of growth are recognizable (Fig. 71).

Circulatory system (Fig. 65). Circulatory system of $B$. stellata identical to the B. agassizii as described above.

Reproductive system (Fig. 66). Ampulla thick and elongated, about two-three times wider than deferent duct; curved, but not convoluted. Spermoviduct branching into two ducts, oviduct leading to female gland mass and other duct leading to prostate. Prostatic portion of deferent duct convoluted; not clearly differentiated from deferent duct. Near deferent duct distal end it joins with elongated penial gland and narrows near into conical penis. Penial gland about four-five times thicker than deferent duct. Penis (in specimen with $18 \mathrm{~mm}$ long alive: length $88 \mu \mathrm{m}$; width $73 \mu \mathrm{m}$ ); completely contractible. Bursa copulatrix and seminal receptacle join vaginal duct 

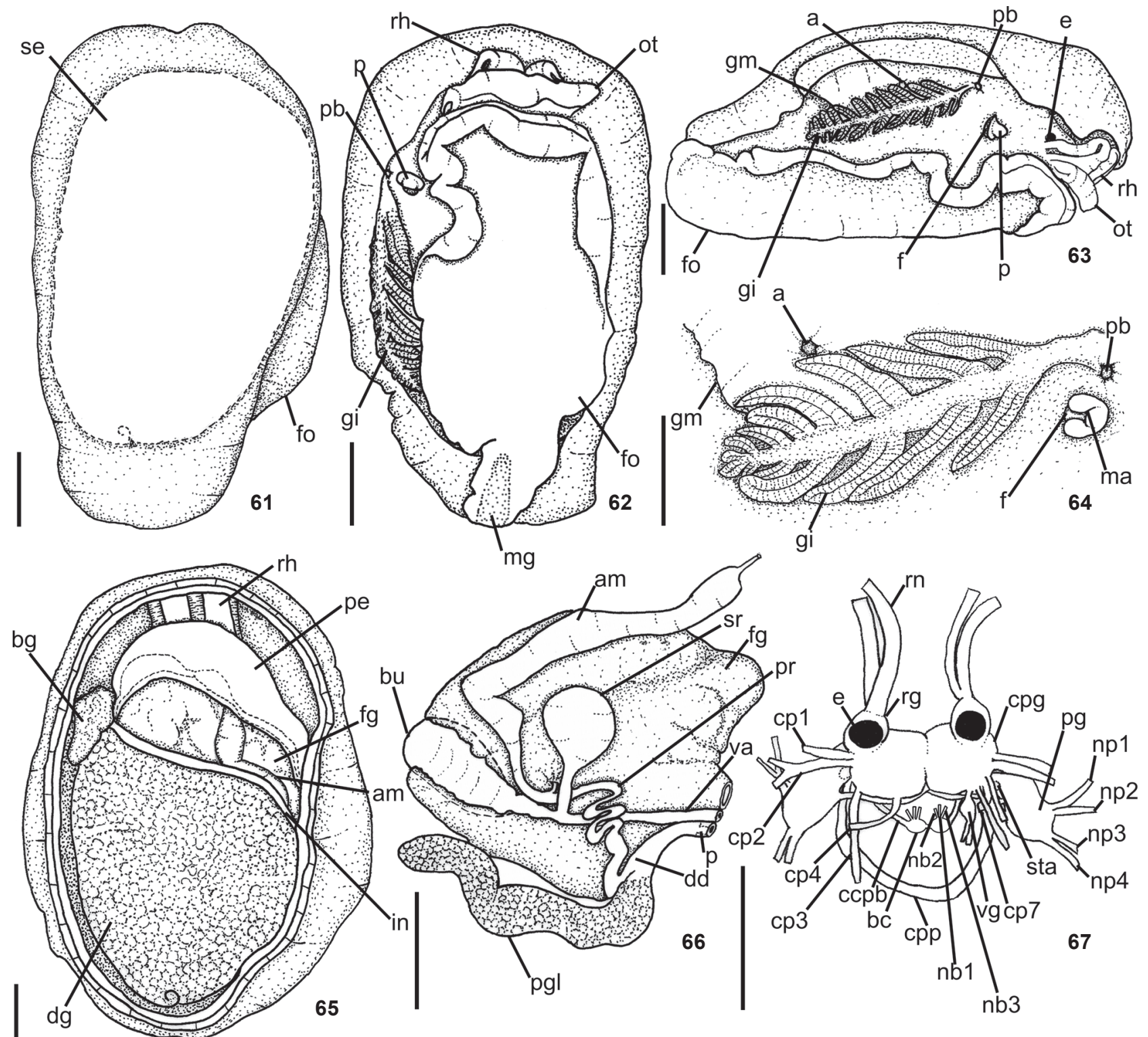

Figures 61-67. Berthella stellata. (61) whole dorsal view, dotted line indicates position of shell internally, MNRJ 31246; (62) ventral view, MNRJ 31246; (63-64) lateral view; (63) MNRJ 31246; (64) detail near gill, MNRJ 30345; (65) dorsal view, organization of internal organs, MNRJ 31333; (66) reproductive system deflected, dorsal view, MNRJ 30345; (67) central nervous system, dorsal view, MNRJ 30345. Scale bars: $1.0 \mathrm{~mm}$.

in its $3 / 4$ distal portion. Rounded bursa copulatrix. Seminal receptacle stalked and elongated; representing $70 \%$ of length of bursa copulatrix. Vagina not convoluted; about same diameter or two times wider than deferent duct. Vaginal opening immediately ventral to penis. Genital aperture surrounded by fold.

Nervous system (Fig. 67). Nervous system of B. stellata very similar to B. agassizii as described above, with the following exceptions: $\mathrm{cp} 2$ bifurcating near base, both cp2a and cp2b inserting dorso-laterally into mantle. Nerves leaving buccal ganglia: nb1 inserting into esophagus; nb2 inserting into salivary ducts; nb3 leading to $\mathrm{m} 5$; connective cerebro-pleural-buccal shortly after nb3.

Digestive system (Figs. 73-85). Digestive system of $B$. stellata very similar to $B$. agassizii as described above, with the following exceptions: Muscle surrounding jaws (mj) strong, welldeveloped (Fig. 79). Jaws light yellow, lighter posteriorly. Each 



Figures 68-70. Berthella stellata, spicules, MNRJ 31330. (68) linear; (69-70) stellate. Scale bar: $15 \mu \mathrm{m}$.

jaw plate showing alternate rows formed by elongated and denticulate elements with cruciform lateral expansion (29 longitudinal and 20 transversal elements, in specimen of $9 \mathrm{~mm}$ long alive; 47 longitudinal and 22 transversal elements, in specimen of $18 \mathrm{~mm}$ long alive); elements consist on a main cusp with 3-5 denticles in each side (Fig. 73), which could be of different sizes and not symmetric; some specimens presents posterior elements flattened in its middle (Fig. 74). Pair of m1va originating in posterior portion of oral canal, running in middle of buccal mass and inserting near radular sac (Figs. 81-82). Single auxiliary muscle m10a absent. Pair of strong retractor muscles originates in most posterior portion of m5 (Fig. 81); separated approximately the anterior $2 / 3$ of length and jointed in its posterior portion, laying above anterior portion of digestive gland.
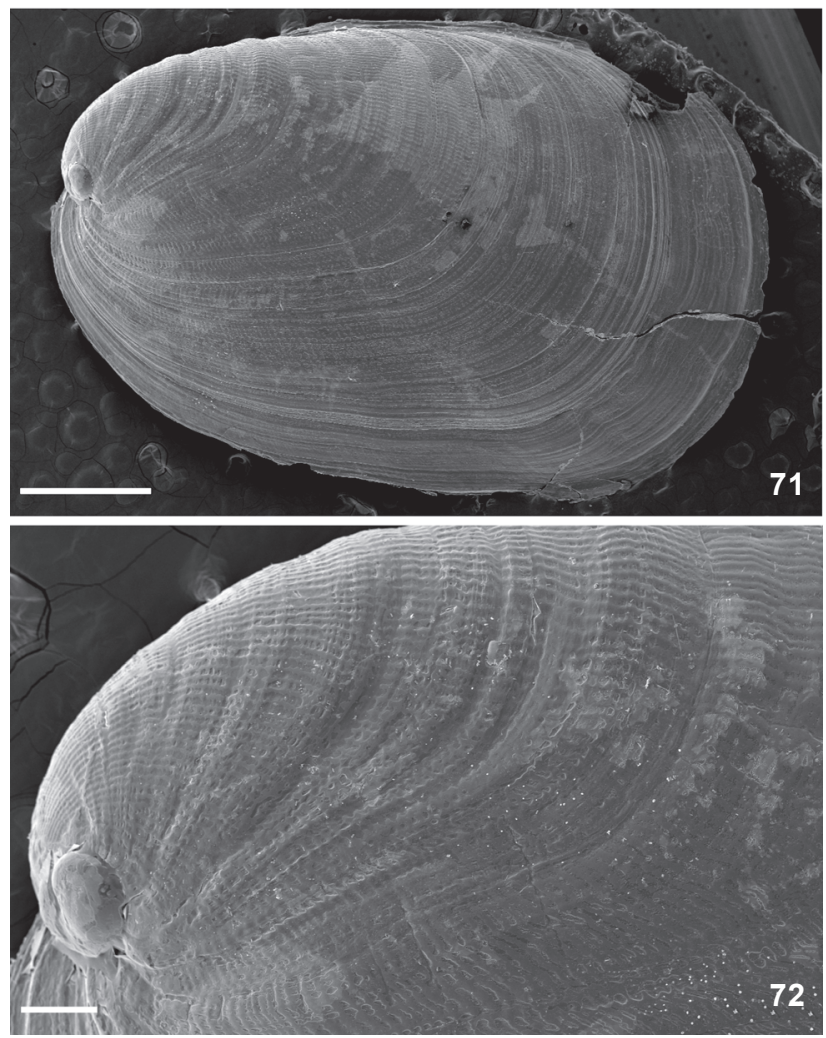

Figures 71-72. Berthella stellata, SEM of shell, MNRJ 31246; (72) detail near protoconch. Scale bars: $71=1.0 \mathrm{~mm}, 72=200 \mu \mathrm{m}$.

Odontophore cartilage resembles a rhombus in outline (Fig. 85). Radula rectangular, two times longer than wide; formula $59 \times$ 53.0 .53 (in specimen of $18 \mathrm{~mm}$ long alive); $49 \times 45.0 .45$ (in specimen of $16 \mathrm{~mm}$ long alive); $46 \times 56.0 .56$ (in specimen of 9 $\mathrm{mm}$ long alive). Radula lacks rachidian tooth (Fig. 75); lateral plates smooth hook shaped, without denticles; base of tooth enlarged (square) and concave; innermost lateral tooth hookshaped and could be smooth (Fig. 75) or with one denticle in its base (Fig. 76); subsequent lateral plates hook-shaped, larger and more developed in center of rows; outermost lateral teeth bifid (Fig. 78), unusually smooth (Fig. 77). Esophagus sac-like tube passing into tube-like stomach (Fig. 84); thin walled. Stomach internally with longitudinal folds (Fig. 84).

Material examined. Puerto Rico: MZSP 121398, 18/xi/1964, G. Warmke coll. [one microscope slides: radula and jaw]. Brazil: Rio Grande do Norte: Baia Formosa: MZSP 97065, 05/vii/2009, V. Padula coll. [1]. Espírito Santo: Guarapari $\left(20^{\circ} 39^{\prime} 28^{\prime \prime} \mathrm{S} /\right.$ 40²8'29"W): MNRJ 34011, 12/x/2014, J. Alvim coll. [1]. Rio de Janeiro: Cabo Frio: Praia das Conchas: MZSP 97539, 16/x/2009, V. Padula coll. [1]; Final do Canal de Itajurú: MZSP 97540, 07/ viii/2009, V. Padula coll. [1]; MZSP 97557, 23/iv/2009, V. Padula coll. [1]; MNRJ 31333, 15/iii/2013, J. Alvim coll. [2 dissected]; MZSP 97529, 01/ix/2010, V. Padula coll. [1]; Ilha do Papagaio: 

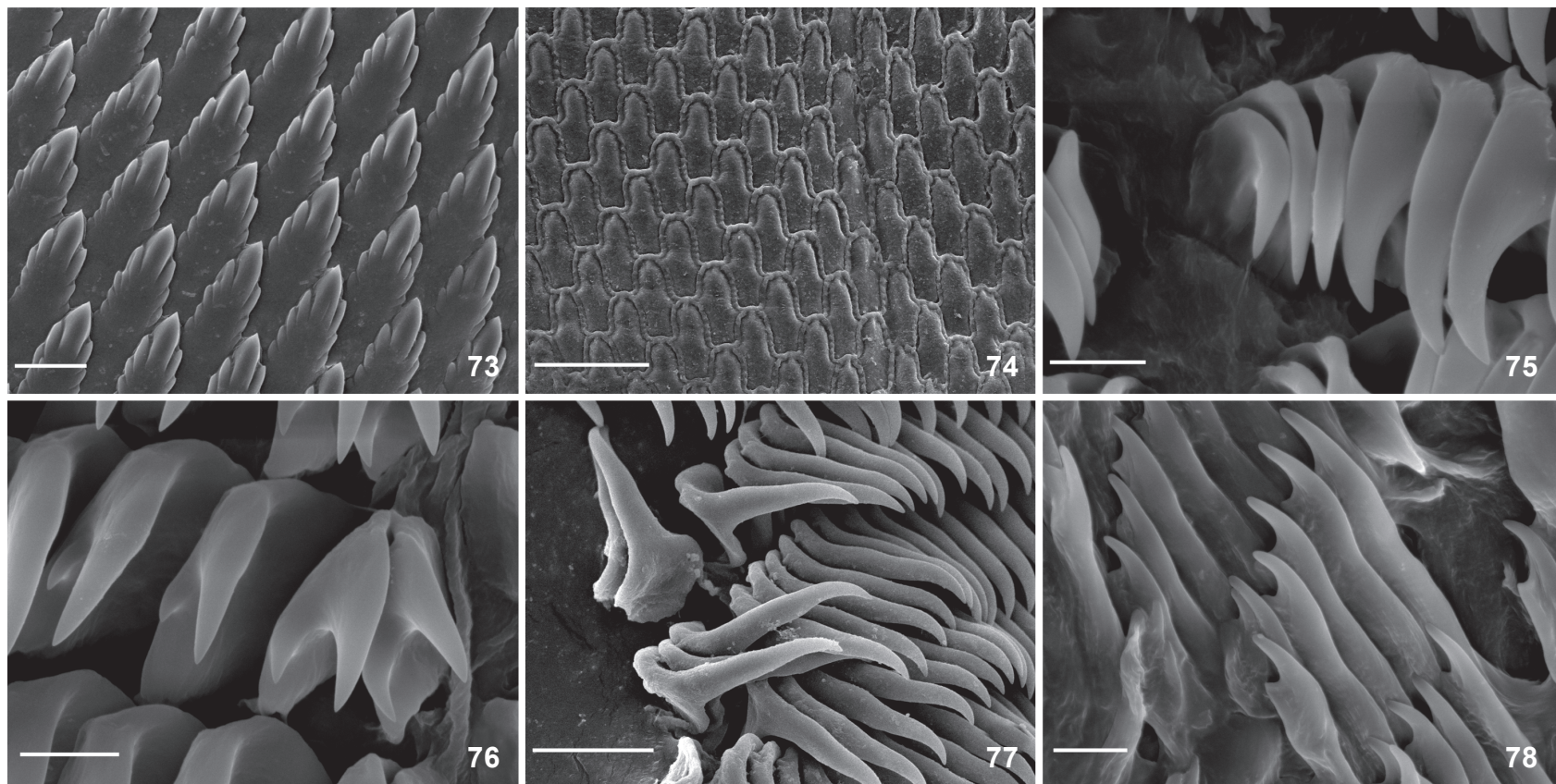

Figures 73-78. Berthella stellata, SEM of jaw and radula. (73-74) elements of jaw; (73) MNRJ 31246; (74) MNRJ 30345; (75-78) radula; (75-76) innermost lateral teeth, MNRJ 31246; (75) smooth; (76) with one denticle in its base; (77-78) outermost lateral teeth; (77) smooth, MNRJ 30345; (78) bifid, MNRJ 31246. Scale bars: 73, $77=20 \mu \mathrm{m}, 74=50 \mu \mathrm{m}, 75-76,78=5 \mu \mathrm{m}$.

MZSP 97514, 30/vii/2008, V. Padula coll. [3]; Arraial do Cabo: Prainha: MNRJ 11020, 13/ii/2007, J. Alvim coll. [1 dissected]; MNRJ 31246, 10/iii/2012, J. Alvim \& P. Romano colls. [3; 2 dissected]; MNRJ 31330, 16/iii/2013, J. Alvim coll. [2; 1 dissected]; Praia do forno: MZSP 25923, vii/1957, Er. Marcus coll. [1]; MNRJ 12784, 19/i/2008, J. Alvim coll. [1 dissected]. São Paulo: Ubatuba, MZSP 121399, part of the holotype of B. tupala, ix/1955 [one microscope slide: 121399]. Santa Catarina: Itapema: Praia do canto: MNRJ 30345, 04/i/2012, J. Alvim coll. [1 dissected].

Specimen records. Indo-Pacific tropics from South Africa (Gosliner 1987 apud GosLIner \& BerTsch 1988); Australia (Burn 1962, Thompson 1970); Marshall Islands (Willan 1984); New Caledonia (Risbec 1928); Pacific Ocean: Hawaii (PeAse 1860, Kay 1979); Mexico: Baja California, Gulf of the California (Gosliner \& Bertsch 1988); Mediterranean Sea: Nice (Risso 1826); Naples (Mazarrelli 1891); Coast of Sicily (VAYsSIÈre 1898); Rovinj (Pruvot-Fol 1954, Thompson 1981); Greece (Gosliner \& Bertsch 1988); Sudanese Red Sea (Heller \& Thompson 1983); Atlantic Ocean: Florida (Ev. Marcus \& Er. Marcus 1967, Er. Marcus \& Ev. Marcus 1970); Puerto Rico (Er. Marcus \& Ev. Marcus 1970); Bahamas (RedFern 2013): Abaco (REDFERn 2001); Panama (BerTsCh 1975); Belize, Curaçao, Bermuda, Honduras, Cayman Islands, Virgin Islands, St. Lucia, Martinique; Venezuela (VALDÉs et al. 2006); Colombia (Ev. Marcus 1984); Grenada (Gosliner \& BerTsCh 1988); Brazil (Er. Marcus 1957): Fernando de Noronha (García et al. 2002); Rio Grande do Norte(present study); Rio de Janeiro(Ev. Marcus \& Er. Marcus 1967): Cabo Frio (Er. Marcus
1958), Arraial do Cabo (present study); São Paulo(ER. Marcus \& Ev. Marcus 1970): Ubatuba, Ilhabela (Er. Marcus 1957); Santa Catarina (present study).

Distribution. Indo-pacific tropics from South Africa; South Pacific Ocean; North Pacific Ocean; Mediterranean Sea; Sudanese Red Sea; Atlantic Ocean: Florida to Brazil (Fernando de Noronha to Santa Catarina).

Remarks. Berthella stellata was originally described from the Mediterranean Sea and is a well-known species with a widespread worldwide distribution. B. stellata is easily recognized by its white-yellowish translucent body surface with scattered or medially situated opaque white markings, sometimes forming a cross. Several species of Berthella were described as having a translucent body with white markings, and for many years they were considered distinct due to their disjunct geographic distributions (e.g., B. tupala, from Brazil, Caribbean Sea and South Africa; B. stellata albocrossata, from Sudanese Red Sea; B. postrema, from Australia; B. pellucida, from Hawaii, Australia and New Caledonia). Gosuiner \& BerTsCH (1988), in a review of Berthella with white markings, concluded that they are all the same species because the variation exhibited throughout the world is expressed in individuals within a single limited geographical area.

In fact, the general color is highly variable in specimens of B. stellata, from translucent whitish to yellowish brown, as well as the opaque white marks on the dorsum, which could have different patterns or be absent (e.g., Risso 1826, PEASE 1860 , 


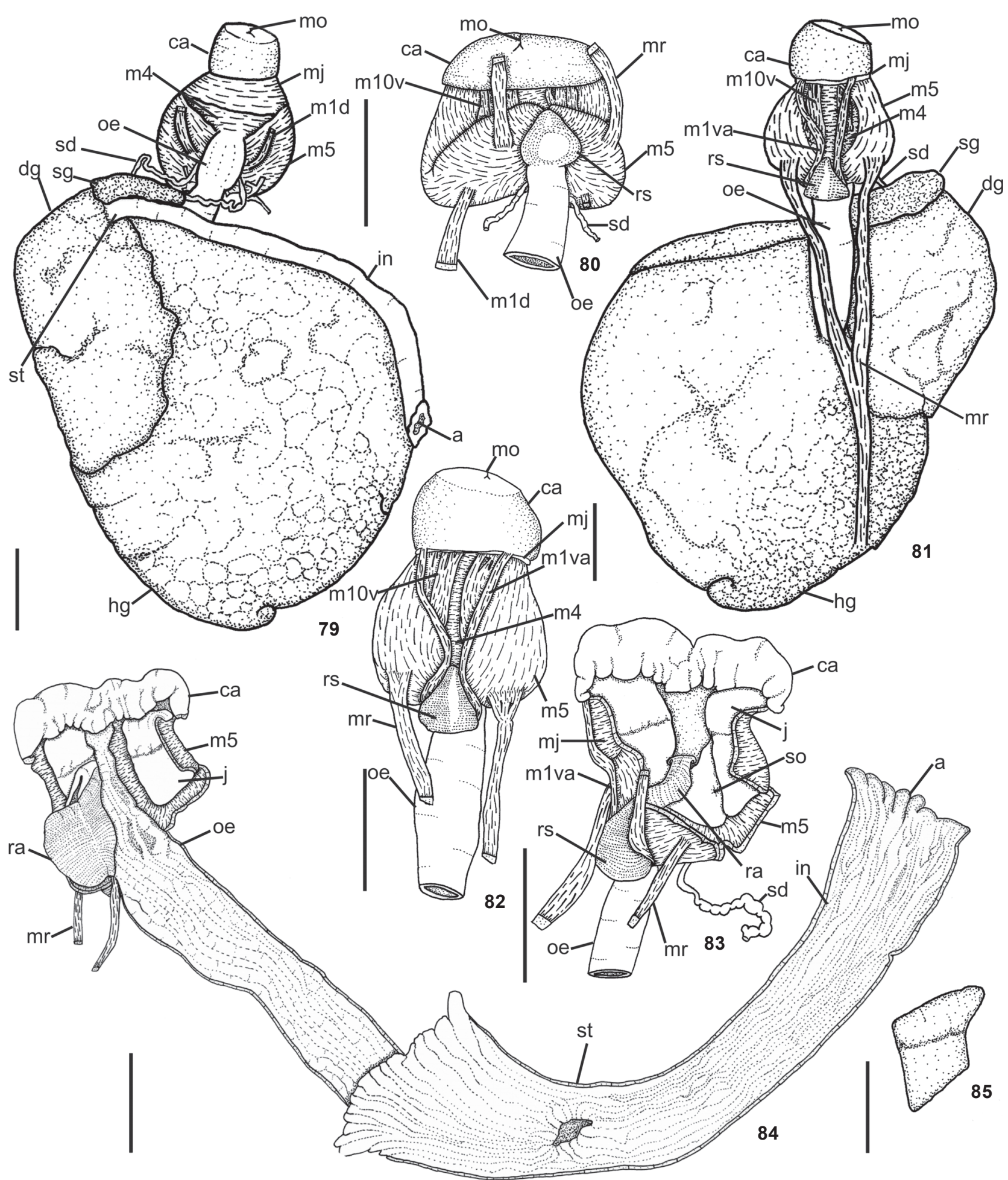

Figures 79-85. Berthella stellata, digestive system, MNRJ 31333. (79-80) dorsal view; (80) pharyngeal bulb with esophagus deflected; (81-82) ventral view; (82) detail of the pharyngeal bulb; (83) pharyngeal bulb partly sectioned longitudinally from ventral side; (84) foregut sectioned longitudinally from ventral side; (85) odontophoral cartilages. Scale bars: 79-84=1.0 mm, $85=0.5 \mathrm{~mm}$. 
VAYsSIÈRe 1898, Thompson 1985, Willan 1984, GosLINER \& BerTsCH 1988). In the specimens from Brazil, the general color of translucent white was the only one found, the yellowish-brownish pigment in fact refers to the visceral mass and sometimes the shell. Gosliner \& BerTsch (1988) noted that some specimens presented yellow tubercles; however, in the specimens from Brazil such tubercles are not present.

The shell of $B$. stellata was described as white or translucent by many authors (RISSO 1826, PEASE 1860, RisBeC 1928), while only ER. MARcus (1957) described it as brown for B. tupala and BurN (1962) as pale fawn for $B$. postrema. In the specimens of the present study, there are two color types: in small live specimens, up to 9 $\mathrm{mm}$ long, the shell is white and very fragile (Fig. 9); in larger specimens the shell is brown, with the first whorl translucent white (Fig. 10) and not fragile. Also, there is a correlation between the length of the shell and its color: white shells are smaller than brown shells. Some intermediate shell color, as light gold, are rare.

The innermost lateral teeth of the radula vary considerably, sometimes in the same specimen; they can be smooth or bear one denticle at the base. GosLINER \& BERTSCH (1988) found all outermost lateral teeth with secondary denticles, as many other authors did (Er. Marcus 1957, Willan 1984, Gosliner 1987 apud GosLINER \& BERTSCH 1988). In most specimens studied here, the outermost lateral tooth has a secondary basal denticle. In only one specimen (MNRJ 30345, from Santa Catarina) the outermost tooth is smooth (Fig. 77). This fact was already reported by VayssiÈre (1898) and Risbec (1928). Therefore, the radula is also a really variable character within this species.

Despite the wide geographic distribution of B. stellata, there are only a few publications describing its reproductive system, fully or partially (e.g., Er. Marcus 1957, Burn 1962, Willan 1984, Ev. Marcus 1984, Gosliner \& Bertsch 1988). Gosliner \& BERTSCH (1988) studied the reproductive system of specimens from different localities and concluded that the duct of the seminal receptacle may join the vagina at the base of the bursa copulatrix or near the middle of the vaginal duct. In specimens from Brazil, the bursa copulatrix and the seminal receptacle join the vaginal duct at its $3 / 4$ distal portion. Er. Marcus (1957) described the reproductive system of $B$. tupala without mentioning the seminal receptacle, which led GosLiner \& BerTsch (1988) to suggest that the description of the arrangement of the reproductive organs was wrong. We agree with this assumption, since B. tupala was originally described based on specimens from Brazil, as the material studied here, and we found the seminal receptacle in all specimens dissected, as expected. BuRN (1962) also described only one allosperm receptacle and that is most likely an error.

Berthella tupala is the only species originally described from Brazil among the synonymies of $B$. stellata. The original description of $B$. tupala, as well as the description in the present work, agrees with the descriptions of B. stellata (e.g., BuRN 1962, Willan 1984, Ev. Marcus 1984, Gosliner \& Betsch 1988). The wide geographical distribution of $B$. stellata is quite questionable. The characters traditionally used to distinguish species of Berthella, external morphology, radula, jaw and reproductive system, are not as useful as previously supposed. Based on available descriptions of $B$. stellata, we cannot conclude whether we are dealing with more than one species or whether there are cryptic species involved, but we believe that molecular data and more detailed descriptions might help this process. In this paper we describe more characters than those used traditionally, since they might turn out to be useful for comparison with further descriptions of specimens of different localities.

\section{Berthellina Gardiner, 1936}

Berthella auct. non Blainville, 1824: VAYsSIÈRE, 1896: 115. Berthellina GARDINER, 1936: 198. Type species by original designation: Berthellina engeli Gardiner, 1936.

Description (adapted from Willan 1983, 1987, THомpson 1970, Ev. Marcus 1984). Body elliptical or convex; internal shell between one-quarter and one fifth the body length, or absent; pedal gland never present; gill rachis smooth; anus at posterior end of gill membrane; radula teeth elongate, lamelliform, with denticles on distal section of posterior edge; jaw elements smooth or denticulate with forward denticles. Pair m4, main dorsal tensor muscle of radula, well developed, originating in lateral region of cartilages, surrounding them ventrally, inserting into subradular membrane. Pair m5, secondary dorsal tensor muscle of radula, covering median portions of cartilage, extending up to dorsal region; originating in posterior surface of cartilages; inserting laterally in mj. Pair $\mathrm{m} 7$ absent. Pair m10d (dorsal) absent. Pair m10v (ventral), protractor muscle of odontophore, connected posterior portion of canal oral with ventral portion of $\mathrm{m} 5$. Single auxiliary muscle $\mathrm{m} 10 \mathrm{a}$, ventral tensor muscle of radula, originating in anterior portion of oral canal, running in middle of buccal mass and inserting into radular sac. Pair of strong retractor muscles originates in most posterior portion of $\mathrm{m} 5$ and radular sac.

Remarks. GARDINER (1936) proposed the genus Berthellina, based on $B$. engeli, to include species with lamellate radular teeth. VAYsSIÈRE (1896) presented his classification scheme for Pleurobranchoidea and described each genus and subgenus of it. However, according to Gardiner (1936), the species called Berthella by VAYsSİ̀re (1896) in fact represents Berthellina. The general features of Berthellina that VAYssière (1896) pointed out were: polygonal elements of the jaw, usually without lateral denticles, and lamellar radular teeth with serrate edges at the upper half of the teeth.

\section{Berthellina circularis (Mörch, 1863) Figs. 86-87, 91-112}

Berthella circularis Mörch, 1863: 31; Vayssière, 1898: 277.

Pleurobranchus circularis: Pilsbry, 1896: 200; Bergh, 1897: 134, figs. 31-37, pl. 10.

Pleurobranchus (Oscanius) amarillus Mattox, 1953: 110, pl. 910. Synonymized by Ev. Marcus (1984). 


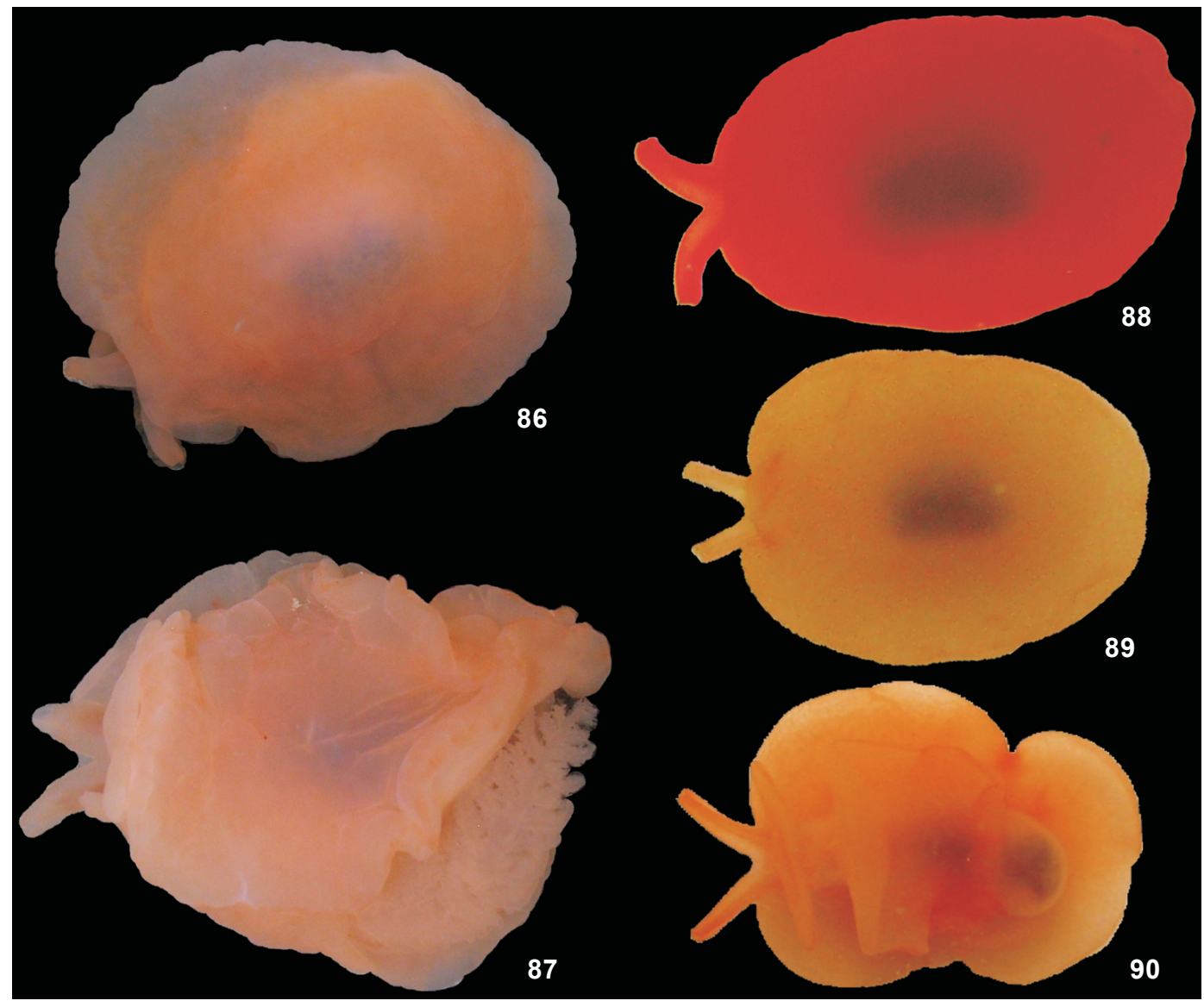

Figures 86-90. Living species of Berthellina from Brazil. (86-87) Berthellina circularis, MNRJ 12935, $21 \mathrm{~mm}$ length of preserved specimen, photo: V. Padula; (86) dorsal view; (87) ventral view; (88-90) Berthellina ignis sp. nov.; (88) dorsal view, MNRJ 95965,18 mm length of preserved specimen, photo: F. Santos; (89) dorsal view, MNRJ 97042, 9 mm length of preserved specimen, photo: V. Padula; (90) ventral view, MNRJ 97042, 9 mm length of preserved specimen, photo: V. Padula.

Berthellina amarillia: Ev. Marcus \& Er. Marcus, 1957: 21; 1962: 465; 1967: 163; 1969: 12.

Berthellina circularis: Ev. Marcus \& Er. Marcus, 1962: 465; Ev. Marcus, 1984: 58, figs. 28-33; García et al., 2008: 208; Rios, 2009: 418

Berthellina quadridens auct. non Mörch, 1863: Ev. Marcus \& Er. Marcus, 1962: 463, figs. 9-13, in part; 1969: 12, fig. 4; Ev. Marcus, 1972: 78; 1979: 132; Rios, 1994: 206, pl. 69, in part; 2009: 417, in part; Valdés et al., 2006: 109, in part; García et al., 2008: 208; Padula et al., 2012: 8; fig. 5C.

Gminotoplax amarillus: Abbott, 1974: 347.

Type material. Not located at the Natural History Museum of Denmark (ZMUC).

Type locality. St. Thomas.

Description. External morphology (Figs. 86-87, 91-93). Living specimens semi-translucent rosy in all parts of body, on laterals color more intense than center and mantle edge (Figs.
86-87). Living specimens up to $31 \mathrm{~mm}$ in length; length of mature preserved specimens $12-26 \mathrm{~mm}$; width 7-14 $\mathrm{mm}$; length of foot 6-21 mm; width of foot 5-12 mm. Body oblong. Mantle covered foot partially (Fig. 91). Dorsum seems smooth, but covered by very small papillae, which were retracted into tiny dorsal perforations. Oral veil thin and trapezoidal, that connects with head region (Fig. 92); laterally, oral tentacles with deep notch, corresponding to almost its length (Fig. 92). Rhinophores rolled joined at their bases, up to $2 / 3$ of the length (Fig. 93). Gill exposed laterally; $1 / 3$ to $1 / 2$ length of body; main rachis smooth with alternated pinnae (Fig. 92); bi-tripinnate pinnae; 13-15 pinnae; 7 pinnae free from body wall, attached by branchial membrane. Anal opening lying over the end of gill membrane. Pre-branchial pore opening approximately beside main rachis (Fig. 92). Nephropore under first pinnae. Genital aperture surrounded by collar (Figs. 92, 94-95). Penis semi-internal, never completely internal when retracted (Figs. 




Figures 91-97. Berthellina circularis. (91) dorsal view, dotted line indicates position of shell internally, MNRJ 12935; (92) lateral view, MNRJ 18770; (93) Dorsal view, organization of internal organs, MNRJ 12935; (94) detail of genital apertures, MNRJ 12935; (95) reproductive system deflected, dorsal view, MNRJ 12935; (96) detail of the connection between bursa copulatrix and seminal receptacle, dorsal view, MNRJ 12935; (97) central nervous system, dorsal view, MNRJ 12935. Scale bars: $91-93=5.0 \mathrm{~mm}, 94-97=1.0 \mathrm{~mm}$. 
92, 94-95). Foot rounded at posterior end and could projected beyond the notum (Figs. 86, 91); metapodial gland absent; anteriorly bilabiated, upper lip notched, smaller than lower one.

Mantle (Figs. 98-100). Mantle and some parts of foot covered by spicules. Spicules stellate (ray length: 350-490 $\mu \mathrm{m}$; ray thickness: 20-30 $\mu \mathrm{m}$ ) (Figs. 98-99); difficult to see how many rays it have, many broken (Fig. 100), some with three-four rays in the same plane. Spicules partially calcareous, but not entirely formed by calcium carbonate because in sodium hypochlorite they partially dissolve, it is also composed of an organic matrix not identified (Fig. 100).

Shell (Fig. 101). White, decalcified and fragile; two times longer than wide; yellowish periostracum. Convex; subquadrangular in outline (Fig. 101). Length $4.3 \mathrm{~mm}$, width $2.7 \mathrm{~mm}$ (in preserved specimen with $22 \mathrm{~mm}$ in length). Spire with 1.5 whorls. Protoconch smooth. Lines of growth distinct; immediately after protoconch, with longitudinal sculptures transverse to lines of growth; anterior portion of last whorl only lines of growth are recognizable. Shell above heart, on right side of blood gland (Fig. 91).

Circulatory system (Fig. 93). Pericardium well developed in anterior portion of body (near cerebro-pleural ganglia). Blood flowing into auricle from gills, kidney and venous sinuses. Efferent branchial vessel connecting gill with the auricle. Auricle on right side, ventricle on left; auricle with thin wall; ventricle muscular. Blood gland small, creamy covering left part of pericardium. Blood gland close or joined to aorta; it covers partially ventricle.

Reproductive system (Figs. 94-96). Ampulla elongated, two times wider than deferent duct; curved, sometimes slightly convoluted (Fig. 95). Spermoviduct branching into two ducts, long oviduct leading to female gland mass, other duct leading to prostate (Fig. 95). Prostate globular and granular; five-seven times wider than deferent duct. Deferent duct not convoluted, narrowing into not cuticular penis and penial gland (Fig. 95). Penis semi-internal, never completely internal when retracted (Fig. 94). Penial gland elongated, not-convoluted. Penis half-moon shape (in preserved specimen with $21 \mathrm{~mm}$ length: length 1.7 $\mathrm{mm}$; in preserved specimen with $25 \mathrm{~mm}$ length: length $1.8 \mathrm{~mm}$ ). Seminal receptacle stalked (Figs. 95-96). Rounded bursa copulatrix; seminal receptacle two times more volume than seminal receptacle (Fig. 96). Vagina not convoluted; two times wider than deferent duct. Vagina opening immediately ventral to penis. Genital aperture surrounded by wide flap (Fig. 94).

Nervous system (Fig. 97). Nerve ring above oral canal. Cerebral and pleural ganglia fused. Eyes located latero-centrally of cerebro-pleural complex; eyes borne upon very short optical nerves. Rhinophoral ganglia placed at bases of rhinophores, near cerebro-pleural ganglia; two main nerves leaving from rhinophoral nerves, runing until distal portion of rhinophores; rhinophoral nerves with many secondary nerves, perpendicular in relation to main nerves. Nerves leaving cerebro-pleural ganglia: cp2 bifurcating near origin, both cp2a and cp2b in-
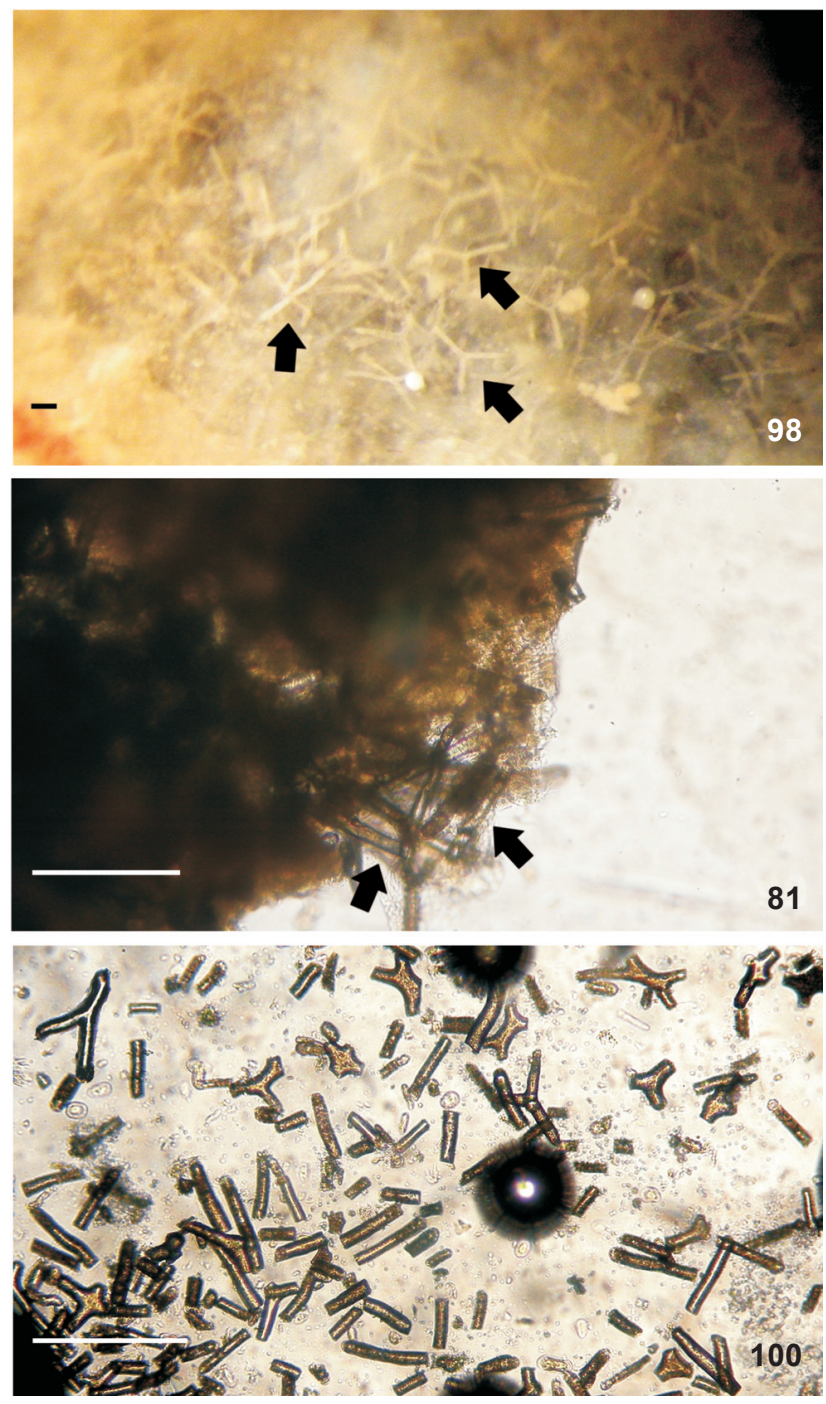

Figures 98-100. Berthellina circularis, stellate spicules, MNRJ 12935. (98) into the foot, black arrow indicates spicules; (99) into the mantle, black arrow indicates spicules; (100) some broken spicules due sodium hypochlorite. Scale bar: $200 \mu \mathrm{m}$.

serting dorsally into mantle; cp6 inserting dorsally into mantle; cp3 runing until median portion of body wall, near anterior portion of digestive gland in left side, inserting into mantle laterally. Connective between visceral and cerebro-pleural ganglia well developed, which has two main nerves. Connective between buccal and cerebro-pleural ganglia leading from ventral view of cerebro-pleural ganglia, in the most anterior portion of ganglion. Nerves leaving buccal ganglia: nb1 bifurcating near origin, both nb1a and nb1b inserts into esophagus; nb2 inserting into salivary ducts; connective cerebro-pleural-buccal shortly after $\mathrm{nb} 1$; nb3 inserting into $\mathrm{m} 4$; nb4 inserting into 



Figures 101-106. Berthellina circularis, SEM. (101) shell, MNRJ 12935; (102-103) elements of jaw, MNRJ 18770; (104-106) radula, MNRJ 18770; (104) innermost lateral teeth; (105) lateral teeth; (106) outermost lateral teeth. Scale bars: $101=200 \mu \mathrm{m}, 102-105=10 \mu \mathrm{m}$, $106=20 \mu \mathrm{m}$.

radula sac; nb5 inserting into retractor muscles of buccal bulb.Connective cerebro-pleural-pedal (ccpp) extremely short and can only be seen after carefully dissecting. Pedal commissure short. Pedal ganglia smaller than cerebro-pleural complex: np1 inserting ventrally into oral veil; np2 inserting anteriorly into foot; np3 innervating foot; np4 inserting ventrally into foot and runs until the most posterior portion of body. In the right side of pedal ganglion, just after the $\mathrm{np} 2$, there is a connective that leads to genital ganglion.

Digestive system (Figs. 102-112). Mouth transversal in middle of snout tip. Oral canal muscular just posterior to mouth, representing approximately $1 / 3$ of pharyngeal bulb length; internally rough (Figs. 111-112). Muscle surrounding jaws (mj) strong, pair of large jaws located in its inner surface (Figs. 111112), mj originating in lateral and dorsal surfaces of oral canal, inserting into lateral and dorsal regions of buccal mass. Jaws amber, lighter posteriorly; jaw of two plates surrounding radula inside buccal cavity; elongated, reaching level of radula. Each jaw plate showing alternate rows formed by elongated elements with a cruciform lateral expansion (104 longitudinal and 70 transversal, in preserved specimen of $12 \mathrm{~mm}$ long and 109 longitudinal and 64 transversal, in preserved specimen of $21 \mathrm{~mm}$ long) (Figs. 102-103); each element with 1-5 small denticles, but some elements could be not symmetric; anterior elements worn. Pair of dorsal jugal muscles m1d (Fig. 107), inserting into m4, connecting to dorsal-anterior end of oral canal. Pair m4, main dorsal tensor muscle of radula, well developed, originating in lateral region of cartilages, surrounding them ventrally, inserting into subradular membrane (Figs. 107-109). Pair m5, secondary dorsal tensor muscle of radula, covering median portions of cartilage, extending up to dorsal region; originating in posterior surface of cartilages; inserting laterally in mj (Figs. 107-109). Pair $\mathrm{m} 7$ absent. Pair m10d (dorsal) absent. Pair m10v (ventral), protractor muscle of odontophore, connecting posterior portion of oral canal with ventral portion of m5 (Fig. 108). Single auxiliary muscle $\mathrm{m} 10 \mathrm{a}$, ventral tensor muscle of radula, originating in anterior portion of oral canal, running in middle of buccal mass and inserting into radular sac (Fig. 108). Pair of strong retractor muscles originates in most posterior portion of m5 and radular sac (Figs. 107-109, 111-112); separated in 1/2 its total length and jointed in its posterior portion, laying above anterior portion of digestive gland (Fig. 108). Odontophoral cartilages subquadrangular in outline (Fig. 110). Radula amber; formula $108 \times 144.0 .144$ (from a preserved specimen with 21 $\mathrm{mm}$ length) and $56 \times 107.0107$ (from a preserved specimen with $12 \mathrm{~mm}$ length). Rachidian tooth absent. Lateral teeth long and slender with subtermial denticles (Figs. 104-106). Innermost lateral tooth with 4-8 irregular denticles (Fig. 104). Subsequent lateral plates larger and more developed in center of rows with 10-17 irregular denticles (Fig. 105). Outermost laterals teeth less developed up to 10 denticles (Fig. 106). Aperture of acid gland located between jaw plates (Figs. 111-112). Duct of acid gland thin (same width as salivary duct) (Fig. 107); runs between stomach (until median portion of stomach) and hermaphrodite gland 


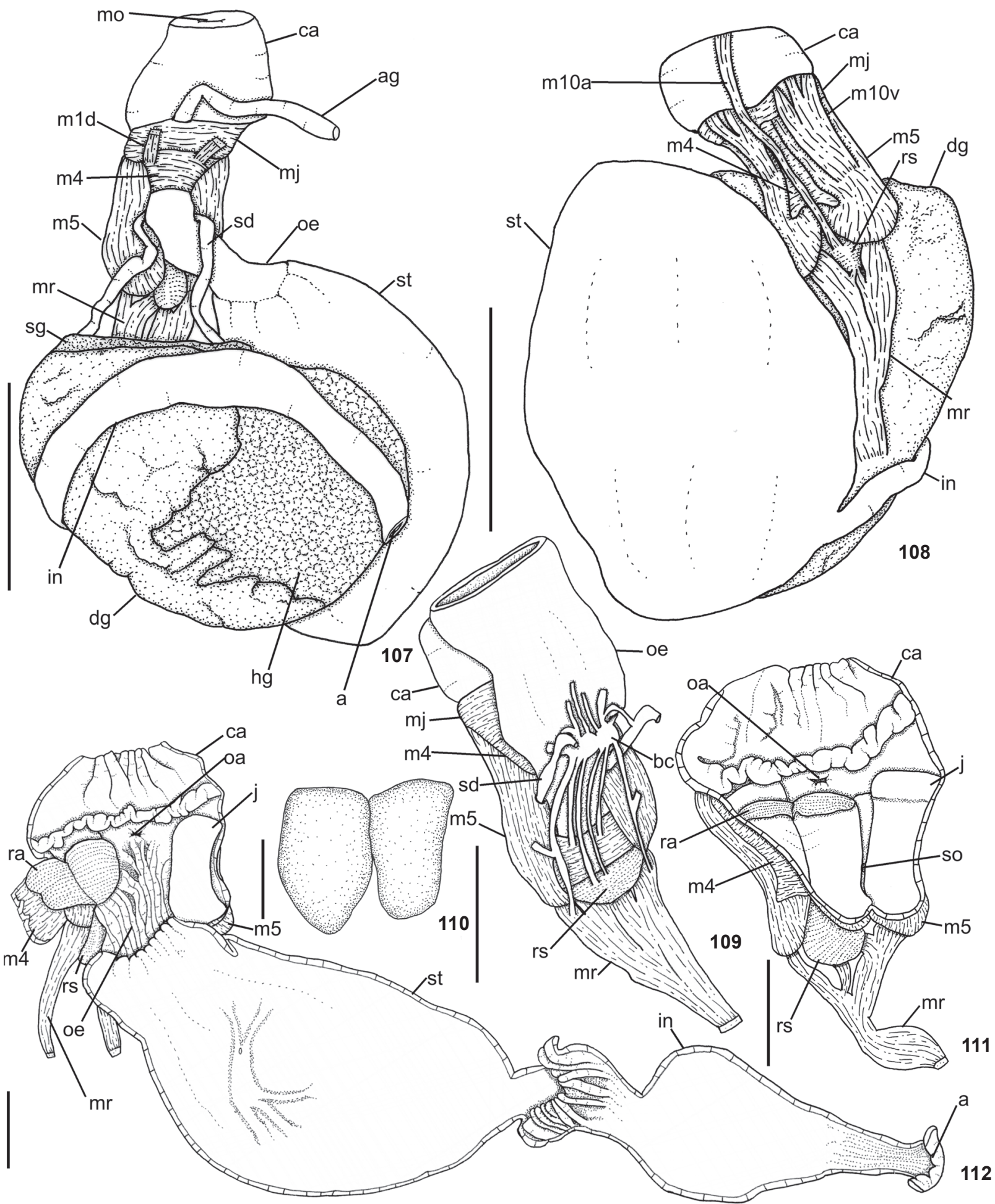

Figures 107-112. Berthellina circularis, digestive system. (107) dorsal view, MNRJ 12935; (108) ventral view, MNRJ 12935; (109) dorsal view, detail of posterior portion with esophagus deflected, MNRJ 12935; (110) odontophoral cartilages, MNRJ 18770; (111-112) foregut sectioned longitudinally from ventral side, MNRJ 12935. Scale bars: $107-108=5.0 \mathrm{~mm}, 109,111-112=2.5 \mathrm{~mm}, 110=1.0 \mathrm{~mm}$. 

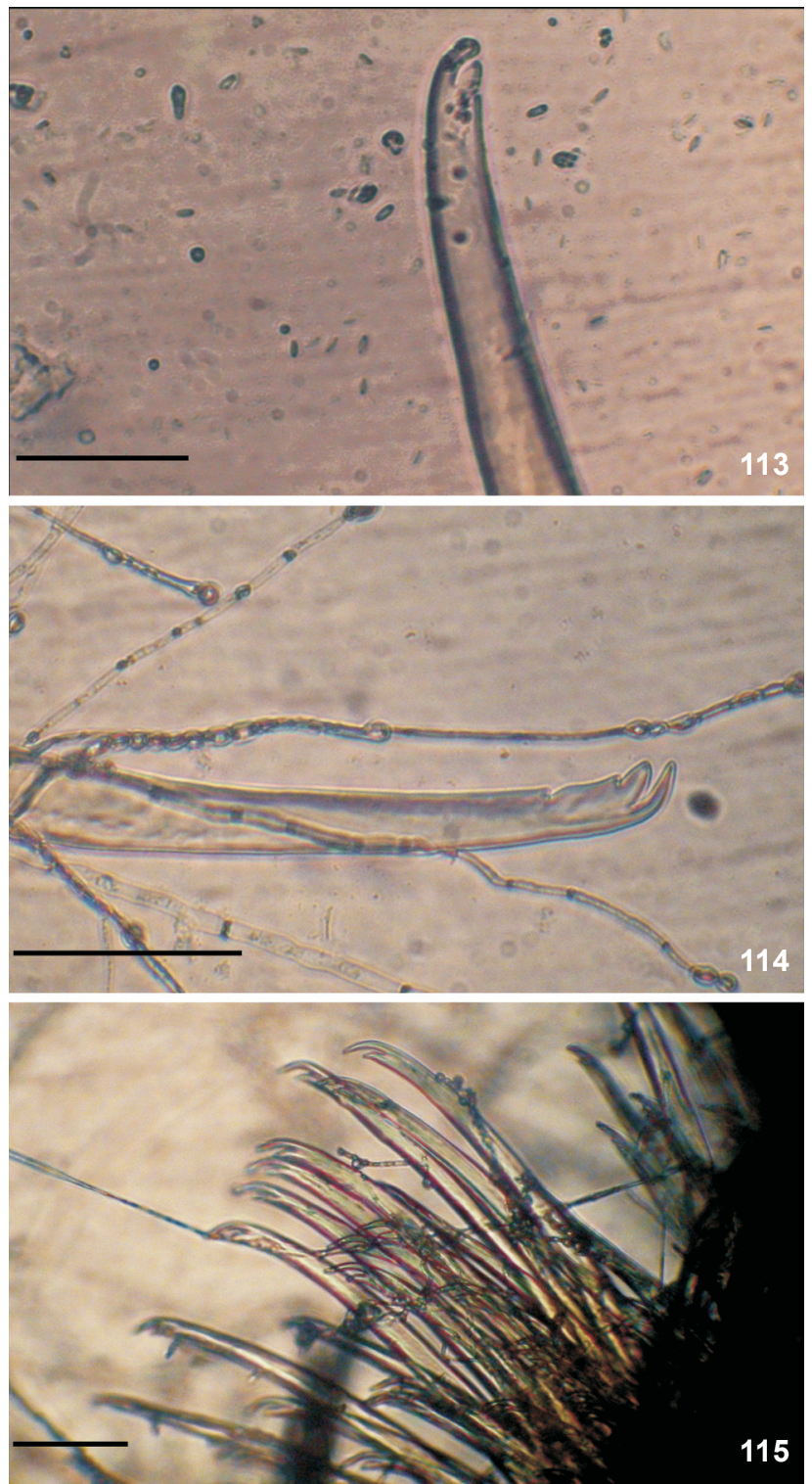

Figures 113-115. Berthellina quadridens, radular teeth. (113) MZSP 75310; (114-115) MZSP 121401. Scale bar: $100 \mu \mathrm{m}$.

and became thin and branches. Esophagus tube-like passing into voluminous stomach (Figs. 107, 112); esophagus internally with longitudinal folds (Fig. 112). Salivary gland tiny, in front of digestive gland (Fig. 107). Ducts of salivary glands entering pharynx musculature laterally to esophagus (Fig. 107), opening into base of pharyngeal cavity between radula and jaw plates (Fig. 111); not convoluted; without a visible ampulla. Stomach saclike, covering all latero-ventral portion of organs (Fig. 108). Posteriorly, stomach passes into intestine (Fig. 108). Intestine long and thin, passing in dorsal portion of digestive and hermaphro- dite glands (Fig. 107); Posteriorly, with thin longitudinal folds (Fig. 112). Salivary, digestive and hermaphrodite glands forming a single aggregate (Figs. 107-108).

Material examined. Brazil: Pernambuco: Recife: MZSP 121404, sta. 55, Akaroa coll. [one lamina radula and jaw platelets]. Alagoas: Saco da Pedra: MNRJ 18770, 02/12/2005, M. Dorigo coll. [2 dissected]; MNRJ 12935, 08/i/2008, V. Padula coll. [2; 1 dissected].

Specimen records. Atlantic Ocean: St. Thomas (Mörch 1863); Puerto Rico (Mattox 1953); Virgin Islands (Ev. Marcus \& Er. Marcus 1962); Brazil: Pernambuco (Ev. Marcus 1972, 1984); Alagoas (Ev. Marcus \& Er. Marcus 1969), Bahia (Ev. Marcus 1979).

Distribution. Caribbean Sea to Brazil (Pernambuco to Bahia).

Remarks. Мӧвсн (1863) described B. quadridens and $B$. circularis (Mörch, 1863) very briefly in the same paper, without distinguishing between the two species. Some years later, BERGH (1897) re-described the types of Mörch (1863) in great detail. However, according to Ev. Marcus (1984), Bergh (1897) mixed material of $B$. circularis and B. quadridens, which resulted in a nomenclatural confusion that lasted for a number of years. Furthermore, some authors considered them as synonyms (ТнOMPSON 1977, VALDÉs et al. 2006), while others as distinct species (Ev. Marcus 1984).

THompson (1977) considered B. circularis and B. amarillius as junior synonyms of $B$. quadridens. MörсH (1863) stated that $B$. quadridens is very similar to B. aurantiaca, from the Mediterranean, except for the radula (B. quadridens has three denticles; $B$. aurantiaca has ten denticles). Based on that information, THOMPSON (1977) concluded that B. amarillius, with 2-10 denticles, complements the gap in denticle number, and synonymized B. quadridens and B. amarillius. Surprisingly, however, he did not consider $B$. quadridens in the synonymy of $B$. aurantiaca. Though THOMPson (1977) broadly explained the synonymy between $B$. quadridens and B. amarillius, he did not discuss the synonymy between $B$. circularis and B. quadridens.

VALDÉs et al. (2006) followed the opinion proposed by THOMPson (1977) and considered B. amarillius and B. circularis as synonymies of $B$. quadridens, since the radular differences are not correlated with external morphological variation.

On the other hand, Ev. Marcus (1984) disagreed with the position of Thомpson (1977) and considered B. quadridens and $B$. circularis as distinct species, with $B$. amarillius as a junior synonym of $B$. circularis due to the similarity in their jaw plates (with 1-4 forward denticles) and the number of radular denticles (up to 25); in contrast, B. quadridens was described with 1-8 forward denticles in the elements of the jaw and with up to five radular denticles.

The radula is so conservative among the Pleurobranchoidea that in most cases it is only used for generic separation and for the most part cannot be used to distinguish species (Ev. Marcus 1984). We follow the position of Ev. Marcus (1984) that B. circularis and B. quadridens are distinct species, since the radula, a conservative character, should be taken into consideration 
when it clearly distinguishes two species. In this paper, the radula of some specimens of B. quadridens mounted by Evelinae Marcus were analyzed (MZSP 121401, MZSP 121402), probably the same material studied by Ev. Marcus (1976) and Ev. Marcus (1984) (see discussion in material and methods section), and it was observed that the majority of teeth have two denticles (Figs. 113 , 115), rarely three or four (Fig. 114). This pattern was not observed in the material of Berthellina from Brazil, since their teeth are highly denticulate, with up to 17 denticles (Figs. 104106). Furthermore, $B$. circularis has fewer denticles in jaw elements, 1-5 forward denticles (Figs. 102-103), than B. quadridens, 1-8 forward denticles. Given what was discussed above we follow Ev. Marcus (1984) in considering that only B. circularis occurs in Brazil and B. quadridens does not. The latter is restricted to the Caribbean Sea and the Pacific coast of Panama, contradicting the authors who recorded it from Brazil (e.g., Ev. Marcus \& Er. Marcus 1969, Ev. Marcus 1972, 1979, Valdés et al. 2006, García et al. 2008, Rios 2009, Padula et al. 2012).

\section{Berthellina ignis sp. nov.}

Figs. 88-90, 116-136

Diagnosis. Odontophore cartilage somewhat rounded anteriorly, posteriorly rectangular (Fig. 135). Elements of the jaw as a main cusp without denticles (Fig. 127) or up to 10 denticles. Innermost lateral tooth with 4-7 irregular denticles (Fig. 129). Subsequent lateral plates larger and more developed in center of rows with 11-19 irregular denticles (Fig. 130). Outermost laterals teeth less developed up to 5-13 denticles (Fig. 131). Acid gland unbranched. Deferent duct thin and convoluted (Fig. 119). Penis conical and semi-internal. Penial gland absent (Figs. 119, 121).

Description. External morphology (Figs. 88-90, 116-117). Living specimens pale orange (Fig. 89) to bright orange (Fig. 88) in all parts of body, on laterals color more intense than center and mantle edge. Length of mature preserved specimens 9-18 $\mathrm{mm}$; width 3-8 mm; length of foot 4-11 mm, width of foot 2-6 $\mathrm{mm}$. Body oblong. Mantle covered foot partially (Figs. 116, 118). Dorsum smooth. Oral veil thin and trapezoidal, that connects with head region (Figs. 116, 118); laterally, oral tentacles with deep notch, corresponding to almost its length. Rhinophores rolled joined at their bases, up to $3 / 4$ of the length (Fig. 118). Gill exposed laterally; $1 / 2$ length of body; main rachis smooth with alternated pinnae (Fig. 117); simple pinnae; $12-19$ pinnae; 4-6 pinnae free from body wall, attached by branchial membrane. Anal opening lying over the end of gill membrane (Fig. 117). Pre-branchial pore opening approximately beside main rachis (Fig. 117). Nephropore under first pinnae. Genital aperture surrounded by wide collar (Figs. 117, 119). Penis semi-internal (Figs. 117, 119). Foot round at posterior end and could projected beyond the notum; metapodial gland absent; anteriorly bilabiated, upper lip notched, smaller than lower one.

Mantle (Figs. 123-125). Mantle covered by sparse spicules. Two types of spicules in mantle: linear, rod-like (length: 120-
$130 \mu \mathrm{m}$; thickness: 5-10 $\mu \mathrm{m})$ (Fig. 123) and stellate, with linear rays (ray length: 27.19-30.0 $\mu \mathrm{m}$; ray thickness: $10 \mu \mathrm{m}$ ) (Fig. 124); stellate spicules difficult to see how many rays it have, some with four rays, because many of them broken into mantle (Fig. 125). Rod-like spicules calcareous; stellate spicules partially calcareous, but not entirely formed by calcium carbonate because in sodium hypochlorite breaks itself, it is also composed of an organic matrix not identified.

Shell (Fig. 126). Shell white to brownish, decalcified, flattened and fragile; two times longer than wide; subquadrangular in outline. Length $4.7 \mathrm{~mm}$, width $2.6 \mathrm{~mm}$ (in preserved specimen with $17 \mathrm{~mm}$ in length). Spire with 1.5 whorls. Protoconch smooth. Lines of growth distinct; immediately after protoconch, with longitudinal sculptures transverse to lines of growth; anterior portion of last whorl only lines of growth are recognizable. Shell located in middle to posterior portion of body (Fig. 126). Circulatory system (Fig. 118). Circulatory system of $B$. ignis sp. nov. identical to the $B$. circularis as described above.

Reproductive system (Figs. 119-121). Ampulla wide, three times wider than deferent duct; curved, not convoluted (Figs. $119,121)$. Spermoviduct branching into two ducts, short oviduct leading to female gland mass, other duct leading to prostate (Fig. 121). Prostate tubular; two-three times wider than deferent duct (Figs. 119, 121). Deferent duct thin and convoluted, narrowing into a not cuticular penis (Fig. 119). Penis semi-internal, never completely internal when retracted (Figs. 117, 119). Penial gland absent (Figs. 119, 121). Penis conical (in preserved specimen with $17 \mathrm{~mm}$ length: length $0.8 \mathrm{~mm}$; width $0.35 \mathrm{~mm}$ ). Seminal receptacle stalked (Fig. 120). Rounded bursa copulatrix; seminal receptacle two-five times more volume than seminal receptacle (Fig. 120). Vagina not convoluted; two times wider than deferent duct (Figs. 119, 121). Vagina opening immediately ventral to penis. Genital aperture surrounded by wide flap.

Nervous system (Fig. 122). Nervous system of B. ignis sp. nov. very similar to $B$. circularis as described above, with the following exceptions: Nerves leaving cerebro-pleural ganglia: cp6 inserting dorsally into mantle, nerve very short; cp4 runing until most posterior portion of body, inserting into body wall, only in the left ganglion of cerebro-pleural ganglia, in the right ganglion absent; cp5 inserting dorsally into mantle. Connective between visceral and cerebro-pleural ganglia short. Nerves leaving buccal ganglia: nb1 bifurcating near origin, both nb1a and nb1b inserting into esophagus; nb2 inserting into salivary ducts; cerebro-pleural-buccal shortly after nb1; nb3 inserting into $\mathrm{m} 4$; nb4 inserting into radula sac; nb5 inserting into retractor muscles of buccal bulb; nb6 inserting into duct of acid gland. Pedal ganglia smaller than cerebro-pleural complex: np1 inserting ventrally into oral veil; np2 and np3 was not observed, nervous system small and difficult to analyze, it could exist; np4 inserting ventrally into foot and runs until the most posterior portion of body.

Digestive system (Figs. 127-136). Digestive system of $B$. ignis sp. nov. very similar to B. circularis as described above, 


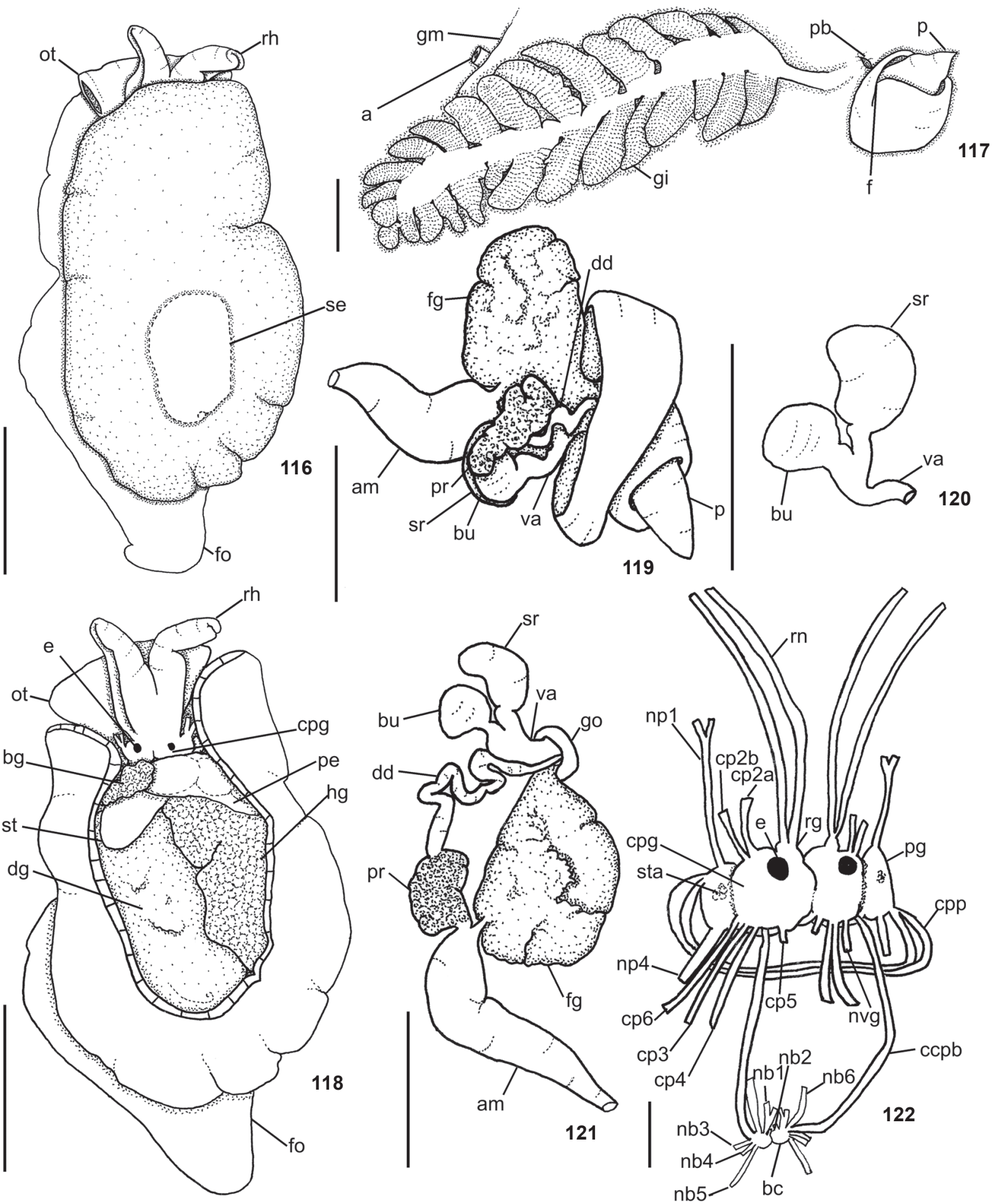

Figures 116-122. Berthellina ignis sp. nov., MNRJ 97039. (116) dorsal view, dotted line indicates position of shell internally; (117) lateral view; (118) Dorsal view, organization of internal organs; (119-121) Reproductive system, dorsal view; (120) detail of the connection between bursa copulatrix and seminal receptacle; (121) reproductive system deflected; (122) central nervous system, dorsal view. Scale bars: $116,118=5.0 \mathrm{~mm}, 117,119-122=1.0 \mathrm{~mm}$. 

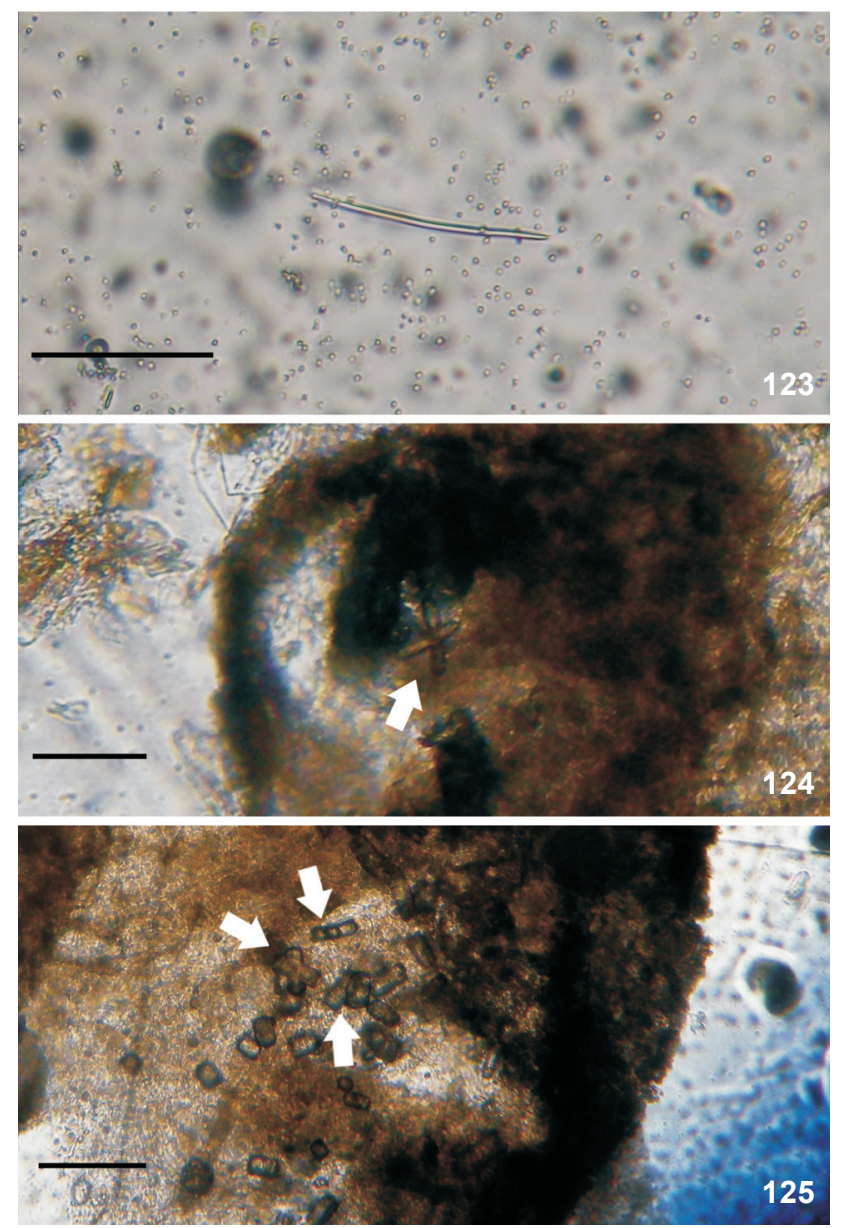

Figures 123-125. Berthellina ignis sp. nov., spicules, MZSP 95965. (123) linear, rod-like; (124) stellate into the mantle, white arrow indicates spicule; (125) some broken spicules into the mantle, white arrows indicate spicules. Scale bar: $100 \mu \mathrm{m}$.

with the following exceptions: Oral canal muscular just posterior to mouth (Figs. 132-133), representing approximately $1 / 2$ of pharyngeal bulb length. Jaws uniformly pale yellow. Each jaw plate showing alternate rows formed by elongated elements with slight cruciform lateral expansion (Figs. 127128); elements consist on a main cusp without denticles in some specimens (Fig. 127), or up to 10 in others (Fig. 128); anterior elements worn. Pair of jugal muscles m1d on dorsal view absent. Pair of strong retractor muscles originates in most posterior portion of $\mathrm{m} 5$ and radular sac; separated in $1 / 3$ its total length and jointed in its posterior portion, laying above anterior portion of digestive gland (Figs. 132-133). Odontophoral cartilages somewhat rounded anteriorly, posterioly rectangular (Fig. 135). Radula dark brown; formula $42 \times 124.0 .124$ (from preserved specimen $13 \mathrm{~mm}$ length); formula $47 \times$ 147.0.147 (from preserved specimen $17 \mathrm{~mm}$ length). Rachid- ian tooth absent. Lateral teeth long and slender with subtermial denticles (Figs. 129-131). Innermost lateral tooth with 4-7 irregular denticles (Fig. 129). Subsequent lateral plates larger and more developed in center of rows with 11-19 irregular denticles (Fig. 130). Outermost laterals teeth less developed up to 5-13 denticles (Fig. 131). Aperture of acid gland located between jaw plates (Fig. 136). Acid gland unbranched. Esophagus tube-like passing into thin stomach (Figs. 132, 136). Salivary gland in front of digestive gland (Fig. 133). Ducts of salivary glands entering pharynx musculature laterally to esophagus (Figs. 132, 134), opening into base of pharyngeal cavity between radula and jaw plates; not convoluted; without a visible ampulla. Stomach elongated and with thin walled, it could be in different states of expansion; internally, could have some thin folds (Fig. 136); stomach passes anteriorly in relation of digestive gland (Fig. 132). Intestine short opening under the gill membrane in the anus; thin wall; internally, smooth (Fig. 136).

Type material. Holotype MZSP 95965, 07/xi/2008, N. Oc. Amorim do Valle coll. [1]. Paratypes: MZSP 121405, type locality, 07/xi/2008, N. Oc. Amorim do Valle coll. [1; 1 dissected]; MNRJ 34212, Barreirinhas, Natal, Rio Grande do Norte, 03/xii/ 2009, M. Delgado Coll. [1; 1 dissected]; MZSP 97039, Barreirinhas, Natal, Rio Grande do Norte, 20/vi/2009, M. Delgado coll. [1 dissected]; MZSP 97042, Barreirinhas, Natal, Rio Grande do Norte, 10/iii/2009, V. Padula coll. [3].

Type locality. Pará $\left(0^{\circ} 1^{\prime} 48^{\prime \prime} \mathrm{S} / 47^{\circ} 24^{\prime} 00^{\prime \prime} \mathrm{W}\right)$, Brazil; $32 \mathrm{~m}$ depth. Specimen records. Brazil: Pará and Rio Grande do Norte. Distribution. Northeastern Brazil.

Etymology. ignis from Latin means fire. The name refers to the bright orange body surface, which resembles a flame.

Remarks. Berthellina ignis sp. nov. presents all diagnostic features of Berthellina (WILLAN 1983), including the absent pedal gland; a smooth gill rachis (Fig. 117); the anus at the posterior end of the gill membrane (Fig. 117); elongated and denticulated radular teeth on the distal section of the posterior edge (Figs. 129-131); smooth jaw elements, or denticulate with forward denticles (Figs. 127-128).

Berthellina ignis sp. nov. is distinguished from $B$. quadridens mainly in the number of denticles in the radular teeth, up to 19 denticles in B. ignis sp. nov. (Figs. 129-131), while $B$. quadridens, whose majority of teeth have two denticles, can have up to five denticles.

The most relevant features that differentiate $B$. ignis sp. nov. from $B$. circularis are (Table 1 ): the deferent duct is convoluted in B. ignis sp. nov. (Fig. 121), while in B. circularis it is straight (Fig. 95); the penial gland is absent in B. ignis sp. nov. (Figs. 119, 121) and present in B. circularis (Fig. 95); the prostate is tubular in B. ignis sp. nov. (Figs. 119, 121) and globular in B. circularis (Fig. 95); the higher number of denticles per jaw element in B. ignis sp. nov. (1-10) (Figs. 127-128) in comparison to B. circularis (1-5) (Figs. 102-103); the jugal muscle (m1d) is absent in B. ignis sp. nov. (Fig. 132) and present in B. circularis 

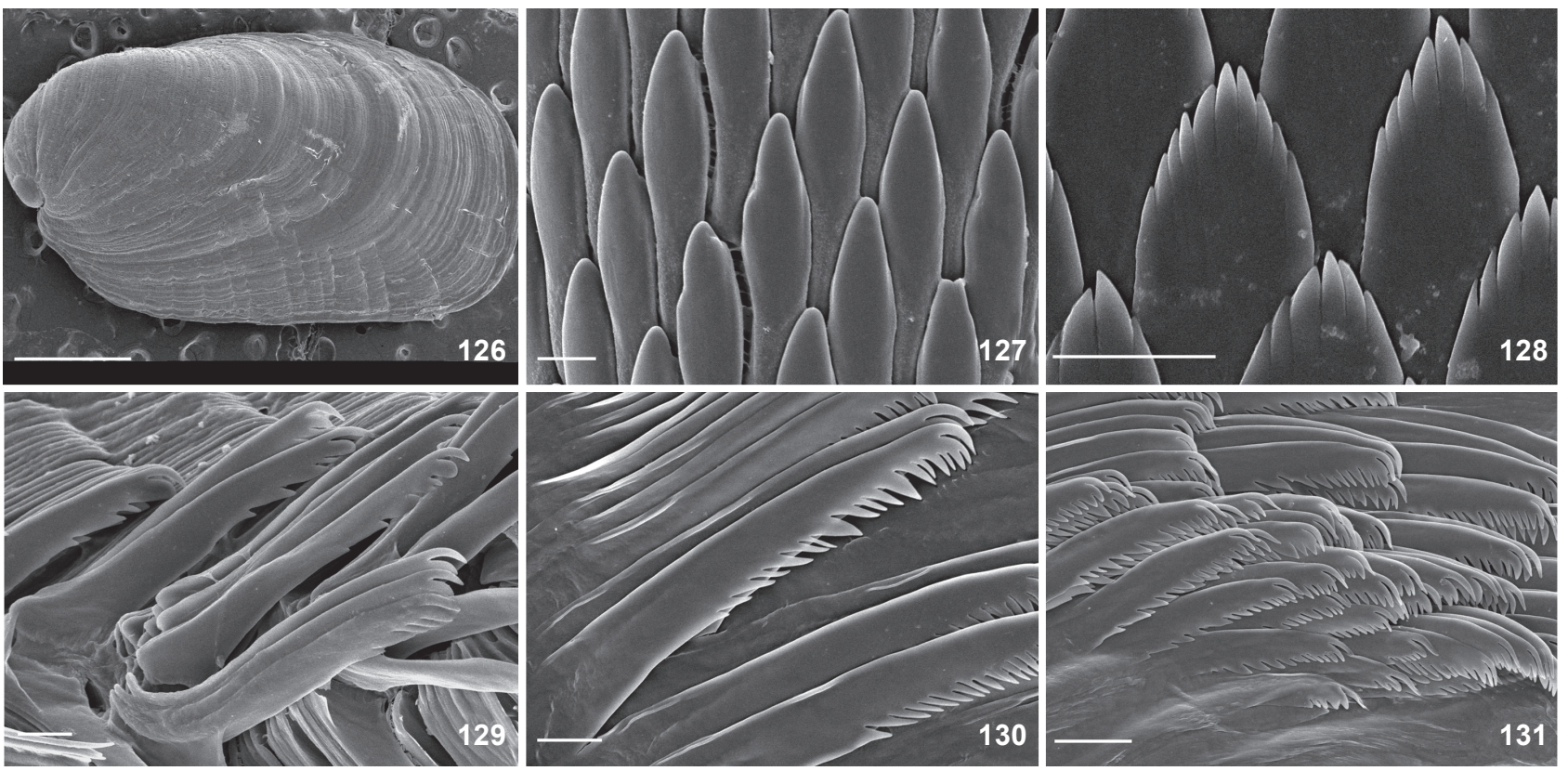

Figures 126-131. Berthellina ignis sp. nov., SEM. (126) shell, MZSP 97039; (127-128) elements of jaw; (127) MZSP 97039; (128) MNRJ 34212; (129-131) radula; (129) innermost lateral teeth, MZSP 95965; (130) lateral teeth, MZSP 97039; (131) outermost lateral teeth, MZSP 97039. Scale bars: $126=1.0 \mathrm{~mm}, 127-130=10 \mu \mathrm{m}, 131=20 \mu \mathrm{m}$.

Table 1. Comparison among Berthellina from Brazil.

\begin{tabular}{|c|c|c|}
\hline & Berthellina circularis & Berthellina ignis sp. nov. \\
\hline Color & Semi-translucent rosy & Bright orange \\
\hline Gill & Bi-tripinnate & Simple \\
\hline Pinnae & $13-16$ & 12-19 pinnae \\
\hline Pinnae free from body wall & 7 & $4-6$ \\
\hline Linear spicules & Absent & Length: $120-130 \mu \mathrm{m}$; thickness: $5-10 \mu \mathrm{m}$ \\
\hline Stellate spicules & $350-490 \mu \mathrm{m}$; ray thickness: $20-30 \mu \mathrm{m}$ & $27.19-30.00 \mu \mathrm{m}$; ray thickness: $10 \mu \mathrm{m}$ \\
\hline Shell position & Shell above heart, on the right side of blood gland & Middle to posterior portion of body \\
\hline Ampulla & $2 \mathrm{x}$ wider than deferent duct & $3 x$ wider than deferent duct \\
\hline Oviduct & Long & Short \\
\hline Prostate shape & Globular & Tubular \\
\hline Prostate width & Five-seven times wider than deferent duct & Two-three times wider than deferent duct \\
\hline Deferent duct & Not convoluted & Convoluted \\
\hline Penial gland & Present, elongated & Absent \\
\hline Seminal receptacle & Two times more volume than bursa copulatrix & 2-5 more times volume than bursa copulatrix \\
\hline Denticles of jaw elements & 1 to 5 & 1 to 10 \\
\hline $\mathrm{m} 1 \mathrm{~d}$ & Present & Absent \\
\hline Retractor muscle & It is separated in $1 / 2$ its total length & It is separated in $1 / 3$ its total length \\
\hline Odontophoral cartilage & Subquadrate & Rounded anteriorly, posterioly rectangular \\
\hline Radula color & Amber & Dark brown \\
\hline Formula radular & $108 \times 144.0 .144 / 56 \times 107.0 .107$ & $42 \times 124.0 .124 / 47 \times 147.0 .147$ \\
\hline Innermost lateral tooth & 4 to 8 denticles & 4 to 7 denticles \\
\hline Lateral teeth & 5 to 8 denticles & 11 to 19 denticles \\
\hline Outermost tooth & 10 denticles & 5 to 13 denticles \\
\hline Acid gland & Branched & Unbranched \\
\hline Stomach & Voluminous & Thin (tube-like) \\
\hline
\end{tabular}

ZOOLOGIA 32 (6): 497-531, December 2015 


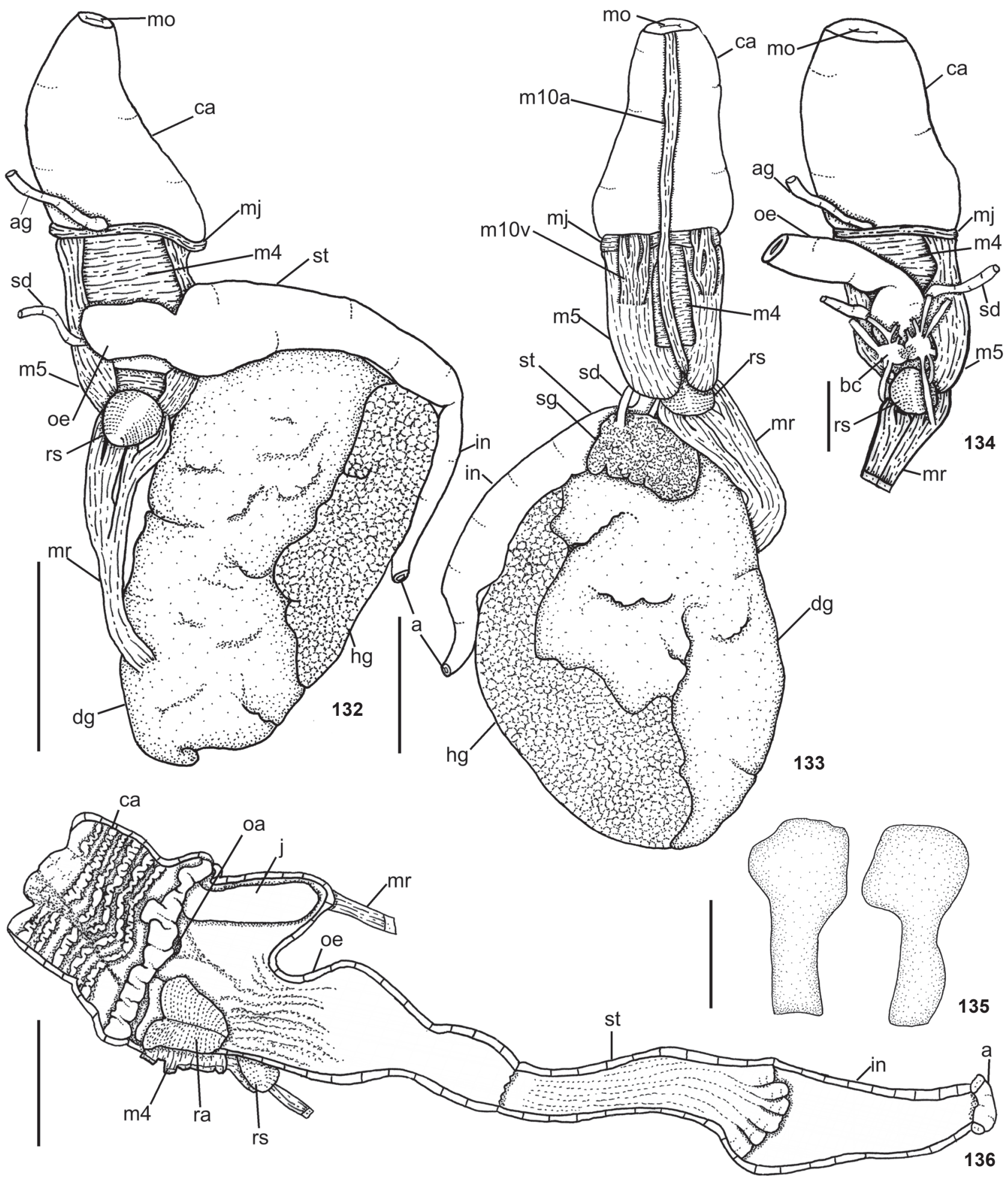

Figures 132-136. Berthellina ignis sp. nov., MNRJ 97039. (132) dorsal view; (133) ventral view; (134) dorsal view, detail of posterior portion with esophagus deflected; (135) odontophoral cartilages; (136) foregut sectioned longitudinally from ventral side. Scale bars: $132-133,136=2.5 \mathrm{~mm}, 134-135=1.0 \mathrm{~mm}$. 
(Fig. 107); the color is pale to bright orange (almost red) in $B$. ignis sp. nov. (Figs. 88-90) and semi translucent rosy in $B$. circularis (Figs. 86-87).

The absence of the penial gland in B. ignis sp. nov. (Figs. $119,121)$, is a rare occurrence in the genus, being only reported for Berthellina edwardsi (Vayssière, 1896) from Macaronesian, by Cervera et al. (2000). Ortea et al. (2014) made a short and general description, which led us to perceive other similarities, such as the red-orange mantle surface and the genital openings surrounded by a thick muscular fold; these two characteristics are usual in Berthellina and do not have a taxonomical significance. Moreover, even though Ortea et al. (2014) described the jaw elements as smooth, without denticles on them, pattern also found in B. ignis sp. nov. (Fig. 127), it was observed jaw elements with up to 10 denticles in other specimens of B. ignis sp. nov. (Fig. 128). OrteA et al. (2014) described the radular teeth of $B$. edwardsi with 2-11 denticles, while $B$. ignis sp. nov. presents 4-19 irregular denticles. The descriptions of B. edwardsi, and its junior synonym, Pleurobranchus lowei Watson, 1897, are short, and do not include the reproductive system. This makes it difficult to compare between $B$. ignis sp. nov. and B. edwardsi. In view of the geographic distribution of these species we are considering them distinct species for now.

\section{DISCUSSION}

Based on the present detailed anatomical study, we conclude that the circulatory and nervous systems do not provide useful characters for species differentiation. For example, between Berthellina, the only difference found in the nervous system was in the nerves that extend from the cerebro-pleural ganglia, cp4 and cp5, which are present in B. ignis sp. nov., but not in B. circularis (Figs. 97, 122).

ORTEA et al. (2014) proposed that the network of subepidermal fibers could be used to characterize Bertellina species, but did not describe or illustrate how to differentiate species based on this feature. In B. circularis and B. ignis sp. nov., such network of subepidermal fibers is present, but we have not been able to distinguish a general pattern.

The radula and jaw elements, when mentioned, are the only features of the digestive system that appear in older descriptions. In search for new characters, we have analyzed the odontophoric muscles and have uncovered a general pattern in the position and presence/absence of extrinsic and intrinsic odontophoric muscles for Berthella and Berthellina. As already observed for Pleurobranchaea (Alvim et al. 2014) and Pleurobranchus (pers. obs.), the odontophoric muscles are useful characters, particularly to distinguish among genera, and in some cases species, and we believe that they should be considered in future descriptions.

Berthella and Berthellina present the pair of the muscle $\mathrm{m} 10 \mathrm{v}$ connecting the $\mathrm{mj}$ with the ventral portion of $\mathrm{m} 5$, al- though the pair of the muscle $\mathrm{m} 10 \mathrm{v}$ connects the mj with the ventral portion of $\mathrm{m} 4$ in Pleurobranchus (pers. obs.) and Pleurobranchaea (Alvim et al. 2014). The pair of the muscle m10d is absent in Berthella and Berthellina; in contrast, Pleurobranchus and Pleurobranchaea present the pair of m10d (ALvim et al. 2014, pers. obs.). Based on these characters, Berthella seems to be more closely related to Berthellina than to Pleurobranchus. These new data may help improve the understanding of the evolutionary history of Pleurobranchidae.

Among the species of Berthella analyzed in the present study, some differences were observed concerning the odontophoric muscles. Berthella agassizii follows the same pattern already reported for other pleurobranchids, with the presence of a single auxiliary muscle $\mathrm{m} 10$ a (pers. obs.), a ventral tensor muscle of the radula, which originates in the anterior portion of the oral canal, running in the middle of the buccal mass and inserting into the radular sac. However, the auxiliary muscle $\mathrm{m} 10 \mathrm{a}$ is absent in $B$. stellata and B. punctata sp. nov., which only present one pair of $\mathrm{m} 1 \mathrm{v}$. This difference is outstanding and it can be the starting point to understand the evolutionary history of the genus and to recover natural groups, since Berthella is currently known as paraphyletic (MARTINOv \& SCHRöDl 2009). The anatomical study of the odontophoric musculature of more species of Berthella is necessary to understand if these patterns are present in other species.

In Brazil, B. punctata sp. nov., B. circularis and B. ignis sp. nov. are restricted to the Tropical Atlantic, in Tropical Northwestern Atlantic provinces, North Brazil Shelf and Tropical Southwestern Atlantic (SpaLdiNg et al. 2007). Berthella punctata sp. nov., B. circularis and B. ignis sp. nov. were not observed in the Warm Temperate Southwestern Atlantic province, despite exhaustive collecting in Rio de Janeiro, São Paulo and Santa Catarina. One possible explanation for species with this distribution was suggested by CoеLho \& Ramos (1972), for Decapoda, in which those species are adapted to warm waters, where the seasonal variation of temperature is reduced.

\section{ACKNOWLEDGMENTS}

We are grateful to Franklin N. Santos (UFES) for their support during the collecting trip in Espírito Santo and for collecting specimens of B. ignis sp. nov.; Marlon Delgado (UFRN) and Vinicius Padula (Zoologische Staatssammlung München) for collecting specimens of B. ignis sp. nov.; Patrícia O.V. Lima (MZSP) and Vinicius Padula for collecting specimens and for the great photographs of B. punctata sp. nov.; Bárbara Romera (MZSP) and Carlo M. Cunha (The Academy of Natural Sciences of Drexel University, Philadelphia) for helping with information about Marcus's collection in MZSP; Luiz Simone (MZSP) for loan of material; Amanda G. da Veiga (UFRJ), for helping with SEM operation. This work was supported by Conselho de Aperfeiçoamento de Ensino Superior (CAPES) (J.A., PhD's scholarship) and FAPERJ (Fundação Carlos Chagas Filho 
de Amparo à Pesquisa do Estado do Rio de Janeiro), through project E-26/110.325/2014 and project E-26/110.068/2014.

\section{LITERATURE CITED}

Аввотт R (1974) American Sea Shells. New York, Van Nostrand Reinhold, $2^{\text {nd }}$ ed., 663p.

Alvim J, Simone LRL, Pimenta AD (2014) Taxonomic review of the genus Pleurobranchaea (Gastropoda: Pleurobranchoidea) from Brazil, with description of a new species. Journal of Molluscan Studies 80: 604-623.

Arnaud P (1978) Révision des taxa malacologiques méditerranens introduits par Antoine Risso. Annales du Muséum d'Histoire Naturelle de Nice 5: 101-150.

BANDEL K (1976) Egg masses of 27 Caribbean opisthobranchs from Santa Marta, Columbia. Studies on the Neotropical Fauna \& Environment 11(1-2): 87-118.

Bergh R (1897) Die Pleurobranchiden. Reisen im Archipel de Philippinen. Weisbaden, Kreidel's Verlag, vol. 7., 116p.

BERTSCH H (1975) Distributional and anatomical observations of Berthella tupala (Opisthobranchia: Notaspidea). Nautilus 89 (4): 124-126.

Blainville HMD (1824) Mollusques, Mollusca, p. 1-392. In: Cuvier F (Ed.). Dictionnaire des Sciences Naturelles. Paris, Levrault, Strasbourg et Paris, Le Normant vol. 32.

BuRn RF (1962) On the new Pleurobranch subfamily Berthellinae (Mollusca: Gastropoda); A Revision and new Classification of the species of New South Wales and Victoria. Memoirs of the National Museum of Victoria 25: 129-148.

Cervera JL, Gosliner TM, Garcia-Gómez JC, Ortea JA (2000) A new species of Berthella Blainville, 1824 (Opisthobranchia: Notaspidea) from the Canary Islands (Eastern Atlantic Ocean), with a reexamination of the phylogenetic relationships of the Notaspidea. Journal of Molluscan Studies 66: 301-311.

Clark KB (1984) New records and synonymies of Bermuda opisthobranchs (Gastropoda). Nautilus 98(2): 85-97.

Coelho PA, Ramos MA (1972) A constituição e a distribuição da fauna de decápodos do litoral leste da America do Sul entre as latitudes $5^{\circ} \mathrm{Ne} 39^{\circ} \mathrm{S}$. Trabalhos Oceanográficos da Universidade Federal de Pernambuco 13: 133-236.

ENGEL H (1927) Westindische opisthobranchiate Mollusken. [II.] Bijdragen tot de Dierlcunde 25: 83-122.

GANTÈs H (1956) Complément a l'étude dês opisthobranches dês cotes Du Marroc. Bulletin de La Société dês Sciences Naturelles et Physiques Du Maroc 36: 257-263.

García FJ, Domínguez M, Troncoso JS (2008) Opistobranquios de Brasil. Vigo, edited by the authors, 215p.

García FJ, Troncoso JS, Dominguez M (2002) New data on the benthic molluscs from the Archipelago of Fernando de Noronha (Brazil), with description of a new species of Aegires Lovén, 1844. Iberus 20: 45-56.

GARDINER AP (1936) Engel's paper on "The English species of the family Pleurobranchidae". Journal of Conchology 20: 195-198.
Gosliner TM, BerTsch H (1988) A Review of the Genus Berthella (Opisthobranchia: Notaspidea) from the Pacific Coast of North America. Veliger 31(1/2): 46-67.

Gray JE (1847) A list of the genera of the Recent Mollusca, their synonyma and types. Proceedings of the Zoological Society of London 15(178):129-219.

Heller J, Thompson TE (1983) Opisthobranch molluscs of the Sudanese Red Sea. Zoological Journal of the Linnean Society 78(4): 317-348.

ICZN (1999) International Code of Zoological Nomenclature. London, International Trust for Zoological Nomenclature, $4^{\text {th }}$ ed., 306p.

IherING HV (1915) Die Opisthobranchien der brasilianischen Kuste. Nachrichtsblatt der Deutschen Malakozoologischen Gesellschaft 47: 133-143.

KAY AE (1979) Hawaiian Marine Shells: Reef and Shore Fauna of Hawaii-Section 4. Mollusca. Honolulu, Bishop Museum Press, 653p.

LEACH WE (1852) Molluscorum Britanniae Synopsis. A synopsis of the Mollusca of Great Britain arranged according to their natural affinities and anatomical structure. London, John Van Voorst.

MacFarland FM (1909) The opisthobranchiate Mollusca of the Branner-Agassiz expedition to Brazil. Leland Stanford Junior University Publications, University Series, \#2, 104p.

Marcus ER (1955) Opisthobranchia from Brazil. Boletim da Faculdade de Filosofia, Ciências e Letras, Universidade de São Paulo, Zoology 20: 89-261.

Marcus ER (1957) On Opisthobranchia from Brazil 2. Journal of the Linnean Society of London (Zoology) 43(292): 390486.

Marcus ER (1958) Notes on Opisthobranchia. Boletim do Instituto Oceanografico, Universidade de São Paulo 7(1-2): 31-78.

Marcus ER, Marcus EV (1970) Opisthobranchs from Curaçao and faunistically related regions. Studies on the fauna of Curaçao and other Caribbean Islands 33(122): 1-129.

Marcus EV (1972) Lista de Opisthobranchia (Mollusca, Gastropoda) coletados pelo Labóratorio de Ciências do Mar, Recife, Brasil. Trabalhos Oceanograficos Universidade Federal de Pernambuco 13: 71-82.

Marcus EV (1976) Opisthobranchia von Santa Marta, Colombia. Studies on the Neotropical Fauna \& Environment 11: 119150.

Marcus EV (1979) Campagne de la Calypso au large de côtes Atlantiques de l'Amérique du sud (1961-1962). I. 31. Mollusca Opisthobranchia. Annales de l'Institut Océanographique, Monaco 55 (Suppl.): 131-137.

Marcus EV (1984) The western Atlantic warm water Notaspidea (Gastropoda, Opisthobranchia), Part 2. Boletim de Zoolologia, Universidade de São Paulo 8: 43-76.

Marcus EV, Hughes HPI (1974) Opisthobranch mollusks from Barbados. Bulletin of Marine Science 24(3): 498-532. 
Marcus EV, Marcus ER (1957) Sea-hares and side-gilled slugs from Brazil. Boletim do Instituto Oceanografico 6(1-2): 3-49.

Marcus Ev, Marcus ER (1962) Opisthobranchs from Florida and the Virgin Islands. Bulletin of Marine Science of the Gulf and Caribbean 12(3): 450-488.

Marcus EV, Marcus ER (1963) Opisthobranchs from the Lesser Antilles. Studies on the Fauna of Curacao and other Caribbean Islands 19 (79): 1-76.

Marcus EV, Marcus ER (1964) Verzeichnis der euthyneuren Meeresschneken Brasiliens. Beitrage zur Neotropischen Fauna 3(3): 195-206.

Marcus EV, Marcus ER (1967) American opisthobranch mollusks Part I, Tropical American opisthobranchs, Part II, Opisthobranchs from the Gulf of California. Studies in Tropical Oceanography 6(1-2): 1-256.

Marcus EV, Marcus ER (1969) Euthyneure Meeresschnecken Brasiliens (2). Beiträge zur Neotropischen Fauna 6: 1-16.

Martynov AV, SchröDl M (2009) The new Arctic side-gilled sea slug genus Boreoberthella (Gastropoda, Opisthobranchia): Pleurobranchoidean systematics and evolution revisited. Polar Biology 32: 53-70.

Mattox NT (1953) A new species of Pleurobranchus from the Caribbean (Tectibranchiata). Nautilus 66: 109-114.

Mazzarelli GF (1891) Intorno alle specie di Pleurobranchus del Golfo di Napoli. Bollettino della Societa dei Naturalisti in Napoli 5: 69-76.

Mörch OAL (1863) Contributions à la faune malacologique des Antilles Danoises. Journal de Conchyliologie, Series 3, 11 : 21-43.

ODHNER NH (1926) Die Opisthobranchien. Further Zoological Results of the Swedish Antarctic Expedition 1901-1903 2(1): 1-100.

Ortea J, Leopoldo M, Caballer M (2014) Contributions to the study of the family Pleurobranchidae Gray, 1827 (Mollusca: Opisthobranchia) in the Macaronesia and the Galapagos Islands. Vieraea 42: 117-148.

Ortea J, Moro L, Caballer M (2012) Notes on Opisthobranchia (Mollusca, Gastropoda) 2: On the validity of the species Berthella africana (Pruvot-Fol, 1953) (Notaspidea, Pleurobranchidae) and the superfluous name Berthella canariensis Cervera, Gosliner, Garcia-Gomez y Ortea, 2000. Vieraea 40: 77-82.

Padula V, Bahia J, Correia MD, Sovierzoski HH (2012) New records of opisthobranchs (Mollusca: Gastropoda) from Alagoas, Northeastern Brazil. Marine Biodiversity Records 5: 1-11.

Pease WH (1860) Descriptions of a new species of mollusca from the Sandwich Islands. Part 1. Proceedings of the Zoological Society of London 28: 18-36.

Pilsbry HA (1896) Philinidae, Gastropteridae, Aglajidae, Aplysiidae, Oxynoeidae, Runcinidae, Umbraculidae, Pleurobranchidae. In: Tyron GW (Ed) Manual of Conchology 16. Philadelphia, Conchological Section of Academy of Natural Sciences of Philadelphia Press, 252p.
Ponder WF, Colgan DJ, Healy J, Nützel A, Simone LRL, Strong Ee (2008) Caenogastropoda, p. 331-383. In: PONDER WF, LindBERG DL (Eds.) Phylogeny and evolution of the Mollusca. Berkeley, University of California Press, 488p.

Pruvot-Fol A (1953) Etude de Quelques Opisthobranches de la cote Atlantique Du Maroc et du Senegal. Travaux de l'Institute Scientifique Chérifien 5: 1-105.

Pruvot-Fol A (1954) Mollusques Opisthobranches. Faune de France 58: 1-460.

Redfern C (2001) Bahamian Seashells: A Thousand Species from Abaco, Bahamas. Boca Raton, Bahamianseashells, IX+280p.

Redfern C (2013) Bahamian Seashells: 1161 Species from Abaco, Bahamas. Boca Raton, Bahamianseashells, 501p.

Rios E (1994) Seashells of Brazil. Rio Grande, Editora FURG, $2^{\text {nd }}$ ed., $368 p$.

Rios E (2009) Compendium of Brazilian Sea Shells. Rio Grande, Evangraf, VIII+668p.

Risbec J (1928) Étude anatomique des gastéropodes Tectibranches de la presqu'î’e de Nouméa, avec description de cinq espèces nouvelles. Archives du Museum d'Histoire Naturelle 3: 37-68.

Risso A (1826) Histoire naturelle des principales productions de l'Europe Méridionale et particulièrement de celles des environs de Nice et des Alpes Maritimes. Levrault, Paris 4, 439p.

Sabelli B, Giannuzzi-Savelli R, Bedulli D (1990) Annotated checklist of Mediterranean marine mollusks. Bologna, Società Italiana di Malacologia, vol. 1, 348p.

Spalding MD, Fox HE, Allen GR, Davidson N, Ferdana ZA, Finlayson M, Halpern BS, Jorge MA, Lombana AL, Lourie SA (2007) Marine ecoregions of the world: a bioregionalization of coastal and shelf areas. BioScience 57: 573-583.

THIELE J (1931) Handbuch der Systematischen Weichtierkunde. Jena, Gustav Fischer, vol. 1, VI+778p.

THомpson TE (1970) Eastern Australian Pleurobranchomorpha (Gastropoda, Opisthobranchia). Journal of Zoology 160: 173-198.

THompson TE (1977) Jamaican opisthobranch molluscs I. Journal of Molluscan Studies 43(2): 93-139.

Thompson TE (1981) Taxonomy of three misunderstood opisthobranchs from the northern Adriatic Sea. Journal of Molluscan Studies 47: 73-79.

Thompson TE (1985) Aposematic colour patterns of two Mediterranean species of opisthobranch molluscs: a proposal for co-operative investigation. Journal of Molluscan Studies 57: 5-21.

Valdés A, Hamann J, Behrens DW, DuPont A (2006) Caribbean Sea Slugs. Gig Harbor, Sea Challengers Natural History Books, 289p.

VAYsSIÈre A (1896) Description des coquilles de quelques espèces nouvelles ou peu connues de Pleurobranchidés. Journal Conchyliologie 44: 113-137.

VAYSSIÈrE A (1898) Monographie de la famille des pleurobranchidés (premiére partie). Annales des Sciences Naturelles Paris 8: 
209-402.

VERRILL AE (1900) The nudibranchs and naked tectibranchs of the Bermudas. Transactions of the Connecticut Academy of Arts \& Sciences 10: 545-550.

Willan R (1978) An evaluation of the notaspidean genera Pleurobranchopsis Verrill and Gymnotoplax Pilsbry (Opisthobranchia: Pleurobranchinae). Journal of Conchology 29: 337-344.

Submitted: 28 June 2015

Received in revised form: 7 October 2015

Accepted: 27 September 2015

Editorial responsibility: Marcos D.S. Tavares
WILLAN R (1983) New Zealand side-gilled sea slugs (Opisthobranchia: Notapidea: Pleurobranchidae). Malacologia 23: 221-270.

Willan R (1984) The Pleurobranchidae (Opisthobranchia: Notaspidea) of the Marshall Islands, Central-West Pacific Ocean. The Veliger 27(1): 37-53.

Willan R (1987) Phylogenetic systematics of the Notaspidea (Opisthobranchia) with a reappraisal of families and genera. American Malacological Bulletin 5: 215-241. 